\title{
Determinantes das Republicações no Mercado Brasileiro: Uma Análise a partir dos Incentivos ao Gerenciamento de Resultados
}

\begin{abstract}
Resumo
A republicação das demonstrações contábeis é considerada uma proxy de qualidade da informação contábil, conforme a literatura sobre o tema (Dechow, Ge e Schrand, 2010). Diante disso, o objetivo do presente estudo foi analisar a relação existente entre as Hipóteses de Gerenciamento de Resultados e as Republicações das Demonstrações Contábeis. O estudo de natureza descritiva, documental e com abordagem quantitativa analisou dados de 344 empresas listadas na BM\&FBOVESPA no período de 1998 a 2014. A análise foi realizada por meio de regressão com dados em painel, testando-se as hipóteses de que o Pacote de Remuneração dos gestores, o Nível de Endividamento e o Tamanho da empresa afetam a Republicação das Demonstrações Contábeis.

Observou-se que o tamanho, o crescimento dos ativos, ser auditado por uma Big4 e a adoção das IFRS tiveram efeito positivo e estatisticamente significativo sobre a probabilidade de republicação das demonstrações. Por outro lado, a adoção da SOX, NivGov têm efeitos negativos e estatisticamente significativos.
\end{abstract}

Palavras-Chaves: Gerenciamento de Resultados; Republicação; Governança Corporativa.

\begin{abstract}
Vagner Antônio Marques
Doutor em Administração pela Universidade Federal de Minas Gerais (UFMG) e Professor na Pontifícia Universidade Católica de Minas Gerais (PUCMG). Contato: Av. Dom José Gaspar, 500, Prédio 14 (ICEG), Coração Eucarístico, Belo Horizonte/MG, CEP: 30.535-901. E-mail: vmarques@pucminas.br
\end{abstract}

Hudson Fernandes Amaral

Doutor em Administração pela Université Pierre Mendes France, Professor na Universidade Federal de Minas Gerais (UFMG) e Professor Catedrático Visitante na Universidade de Lisboa (ISEG/ULISBOA). Contato: Av. Antônio Carlos, 6627, Sala 4030, Prédio FACE, Pampulha, Belo Horizonte/MG, CEP: 31.270-901.

E-mail: hfamaral@face.ufmg.br

\section{Antônio Artur de Souza}

$\mathrm{PhD}$ in Management Science pela University of Lancaster e Professor na Universidade Federal de Minas Gerais (UFMG). Contato: Av. Antônio Carlos, 6627, Sala 4030, Prédio FACE, Pampulha, Belo Horizonte/MG, CEP: 31.270-901.

E-mail: artur@face.ufmg.br

Kleyverson Leonardo dos Santos Bacharelando em Ciências Contábeis pela Pontifícia Universidade Católica de Minas Gerais (PUCMG) e Bolsista de Iniciação Científica do Curso de Ciências Contábeis. Contato: Av. Afonso Vaz de Melo, 1200, Barreiro, Belo Horizonte/MG, CEP: 30550-040.

E-mail: kleyverson12@hotmail.com

Pedro Henrique Rodrigues Belo Bacharelando em Ciências Contábeis pela Pontifícia Universidade Católica de Minas Gerais (PUCMG) e Bolsista de Iniciação Científica do Curso de Ciências Contábeis. Contato: Av. Afonso Vaz de Melo, 1200, Barreiro, Belo Horizonte/MG, CEP: $30550-040$.

E-mail: pedrohenrique1550@hotmail.com 


\section{Introdução}

As decisões financeiras tomadas pelos usuários externos são realizadas a rigor, a partir do conjunto de informações disponíveis no mercado, incluindo as demonstrações contábeis (Chalmers, Clinch, \& Godfrey, 2011). Nesse sentido, eles esperam que as informações divulgadas periodicamente pelas empresas sejam, fidedignas, livres de erros e vieses (Mackenzie, Coetsee, Njikizana, Chambobo, Colyvas \& Hanekom, 2013).

Ocorre que diversas questões podem prejudicar a adequada mensuração, reconhecimento e divulgação das informações financeiras, tais como características dos indivíduos (Jensen \& Meckling, 1994), a flexibilidade das normas de contabilidade (Watts, 1992) e falhas cognitivas (Chen \& Chih, 2005). No âmbito das finanças, esse debate é recorrente, pois se referem aos problemas de agência e demandam de uma estrutura de governança para mitigá-los.

Segundo Brickley e Zimmerman (2010), a governança corporativa refere-se a todo mecanismo utilizado para monitorar e alinhar os interesses dos gestores com os dos acionistas. Entretanto, nem todo mecanismo de governança é adequado, pois ele pode implicar um custo de agência efetivo, sem o devido benefício esperado. Esse efeito adverso foi inclusive um dos argumentos utilizados pelos opositores à promulgação da Lei Sarbanes-Oxley (SOX), lei Norte-americana que obrigou as empresas que negociavam ações na New York Exchange Commission (NYSE) a implantarem sistemas de controles internos mais robustos, eficazes, mitigando a possibilidade de ocorrência de fraudes como a ocorrida na Enron (Iliev, 2010).

Nos últimos anos, tem havido um esforço do Financial Accounting Standards Board (Fasb) e do International Accounting Standards Board (Iasb) para desenvolverem um conjunto de normas contábeis de alta qualidade, de modo a aumentar a relevância e qualidade das informações contábeis (Dechow \& Schrand, 2004). Isso tem implicado um processo de convergência e harmonização de normas que no Brasil culminou na adoção, a partir de 2008, do padrão International Financial Reports Standard (IFRS) (Martins, 2012). Entretanto, essas ações podem não necessariamente implicar em melhorias significativas na qualidade das informações, pois aspectos culturais, educacionais e jurídicos podem resultar em interpretações diferentes e práticas não homogêneas (Ball, 2006).

Apesar da adoção de normas, como a SOX e as IFRS, não se conhecem os seus efeitos reais em termos de melhoria da qualidade da informação contábil (Marques, 2016). Primeiro, porque essas normas são relativamente recentes; segundo, porque qualidade da informação financeira é um constructo amplo e, operacionalmente, complexo de se mensurar (Francis, Olsson, \& Schipper, 2006); terceiro, que diversas são as métricas para avaliação da qualidade da informação financeira e não se avaliou o efeito da adoção em todas elas (Dechow, Ge, \& Schrand, 2010).

A literatura sobre qualidade da informação financeira prioriza a avaliação do gerenciamento de resultados, da persistência dos lucros, do conservadorismo e da relevância do valor (DeFond, 2010). Logo, os estudos sobre as republicações das demonstrações têm sido negligenciados ou têm ficado à margem nos estudos sobre a temática, mesmo sendo consideradas como indicativo de gerenciamento prévio de resultado e terem demonstrado um crescimento nas últimas décadas (Hee, 2011; Huber \& Bochner, 2012).

As republicações consistem na reelaboração e divulgação das informações financeiras quando um erro ou omissão materiais são identificados posteriormente à divulgação e publicidade delas (He \& Chiang, 2013). Elas podem ocorrer espontaneamente ou de ofício e são, segundo Dechow, Ge e Schrand (2010) uma das formas de se avaliar a qualidade das demonstrações financeiras, pois ela sinaliza a existência de manipulação intencional dos resultados contábeis.

O gerenciamento de resultados pode decorrer de diversos incentivos, sendo estudado a partir de três principais hipóteses, a saber: (i) oportunismo dos agentes, (ii) nível de endividamento e (iii) custos políticos (Martinez, 2001). O oportunismo dos agentes refere-se à possibilidade de os gestores manipularem as informações contábeis com vistas a maximizarem seu pacote de remuneração corrente ou futuro (Healy, 1985). Por sua vez, a hipótese do nível de endividamento considera que os gestores poderão manipular as informações contábeis com vistas a atender a cláusulas contratuais (debt covenants/leading agreemeents) e também reduzir a percepção de risco acerca da companhia (Dhaliwal, 1985). 
Por fim, os Custos Políticos referem-se ao gerenciamento de resultados com o objetivo de não chamar a atenção para si perante os sindicatos, reguladores, competidores, etc. (Watts \& Zimmermann, 1978; Jones, 1991, Key, 1997). Diante desse contexto, o presente estudo buscou responder à seguinte pergunta: qual é a relação entre a republicação das demonstrações financeiras e os incentivos ao gerenciamento de resultados? Assim, o objetivo deste estudo foi verificar se o pacote de remuneração dos gestores, o nível de endividamento e o tamanho da empresa afetam na republicação das demonstrações financeiras, uma das proxies de qualidade da informação contábil. Adicionalmente, observou-se o efeito do ambiente normativo e regulatório sobre as republicações.

Estudos dessa natureza se justificam pela necessidade de se entenderem as determinantes da republicação e se essa proxy de qualidade da informação financeira sofre influência de variáveis que operacionalizam as hipóteses que motivam o gerenciamento de resultados (Shelton, Owen-Jackson, \& Robinson, 2011). Além disso, a adoção da SOX e das IFRS tiveram objetivos de mitigar os conflitos de agência e melhorar a qualidade das informações financeiras. O estudo buscou contribuir com a literatura da área de Contabilidade e Finanças, apresentando evidências empíricas sobre as determinantes das republicações das demonstrações financeiras e o efeito do ambiente normativo sobre as mesmas. Dentre as implicações empíricas esperadas, destaca-se sinalização aos reguladores e participantes do mercado quanto às possíveis variáveis que afetam na probabilidade de se republicarem as demonstrações, possibilitando o estabelecimento de políticas de monitoramento que considerem tais informações.

A pesquisa de natureza descritiva, documental e com abordagem quantitativa, utilizou uma amostra de 344 empresas por meio da análise de regressão com dados em painel para atingir o objetivo. Os resultados evidenciaram que o tamanho e o crescimento dos ativos aumentam a probabilidade de chances de se republicarem as demonstrações contábeis. Do mesmo modo, a adoção do IFRS e o fato de ser auditado pelas Big4 aumentam na razão de chances de se republicarem. Entre as variáveis que reduzem essa probabilidade de republicação, destacaram-se o Retorno sobre os Ativos (ROA) e a Remuneração dos Diretores.

O artigo está dividido em cinco seções, incluindo esta introdução. Na seção dois, apresentam-se os principais suportes teóricos para o desenvolvimento das hipóteses e discussão do tema. Na seção três, apresentam-se os procedimentos metodológicos adotados, destacando-se os modelos, operacionalização das variáveis e testes utilizados no estudo. Na seção quatro, registram-se os resultados, fazendo-se uma discussão à luz do referencial teórico apresentado no referencial teórico. Por fim, na seção cinco, estão as considerações finais, limitações do estudo e sugestões para pesquisas futuras.

\section{Referencial Teórico}

\subsection{Teoria da Agência e os princípios de Governança}

De acordo Jensen e Meckling (1976), os gestores contratados pelos acionistas têm como objetivo principal a maximização do valor da empresa, isso porque, com a separação entre a propriedade e o controle, os principais (acionistas) terceirizam a gestão com a expectativa de que os agentes (gestores) buscarão alcançar as metas definidas previamente. Entretanto, alguns problemas são inerentes ao processo. Primeiro, que os agentes são automaximizadores, avaliadores, criativos e com desejos ilimitados (Jensen \& Meckling, 1994). Segundo que, como os contratos são incompletos e não conseguem eliminar totalmente o risco moral, os agentes podem utilizar dessas imperfeições contratuais para maximizarem seu próprio bem-estar, gerando o risco de seleção adversa (Aghion \& Holden, 2011).

Diante disso, a firma, como um nexo de contratos, utiliza-se de diversos instrumentos para reduzir o risco moral e as anomalias comportamentais que potencializam a seleção adversa (problemas de agência). Lambert (2001) destaca que os agentes tenderão a priorizar seus interesses para (1) reduzir o esforço para o trabalho, (2) desviar de recursos para uso ou consumo, (3) proteger sua reputação e seu efeito sobre o pacote de remuneração futuro e (4) mitigar o risco. 
As evidências de que os problemas de agência fazem parte do ambiente de negócios são muitas (Di Pietra, McLeay, \& Ronen, 2014). Young \& Peng (2013) observaram que, no período de 1995 a 2009, as fraudes relacionadas à receitas e ao reconhecimento fictício de operações foram os principais motivos de Accounting \& Auditing, Enforcement Releases (AEER). (2015) Lisic, Silveri, Song e Wang (2015) complementam que diante do risco iminente de ocorrência dos problemas de agência, os ambientes regulatórios e institucionais assumem um papel importante.

Nesse cenário, desde a década de 1980, o debate sobre a governança corporativa tem se intensificado, isso porque a recorrência de casos de fraudes contábeis e a maior conexão entre os mercados financeiros e de capitais fizeram emergir uma preocupação global que culminou em: (i) maior preocupação dos agentes econômicos com o ambiente regulatório em que atuam; (ii) na promulgação de normas que atribuíram maior responsabilidade aos gestores pelo sistema de controle interno; (iii) promulgação de normas que protejam os investidores (principalmente os não controladores); (iv) estabelecimento de padrões mínimos de governança aceitos por adesão; e (v) melhoria das normas de contabilidade (Ball, 2006; Brickley \& Zimmerman, 2010; Dechow, Ge, \& Schrand, 2010; Di Pietra, McLeay, \& Ronen, 2014).

Conforme se observa na Figura 1, em síntese, todos esses esforços fundamentam-se nos princípios de Governança Corporativa. Entende-se por Governança Corporativa todo mecanismo interno e externo que tem como objetivo alinhar os interesses entre os agentes e os principais e mitigar os problemas de agência (Armstrong, Guay, \& Weber, 2010). O agente (gestor), assumindo a gestão de recursos em nome dos principais, se obriga a prestar contas (accountabillity) de forma transparente, equânime e em conformidade com as normas e legislações vigentes (Brown \& Caylor, 2009; Yoo \& Jung, 2015).

A Comissão de Valores Mobiliários (CVM) sugere uma Estrutura de Governança Corporativa (EGC) ideal (Comissão de Valores Mobiliários, 2016). Conforme se observa na Figura 1, incluem diversos mecanismos específicos, destacando-se: (1) controles internos, (2) sistema contábil, (3) auditoria, (4) legislação societária, (5) reguladores e (6) autorregulação. Os controles internos são manuais e normas de procedimentos que buscam minimizar o risco de expropriação e/ou ineficácia no processo de execução das atividades.

De acordo com Ronen (2014), o caso Enron expôs as fragilidades dos sistemas de controle internos, mas, por outro lado, estimulou a atribuição de responsabilidades mais bem definidas aos gestores e a definição de controles mis estruturados. Por sua vez, o sistema contábil, ao mesmo tempo que figura como mecanismo de controle, monitoramento e redução da assimetria (Sunder, 2014), serve como instrumento de manipulação, pois a flexibilidade das normas de contabilidade possibilita que os agentes a utilize para atender a objetivos específicos (Watts, 1992; Ball, 2006).

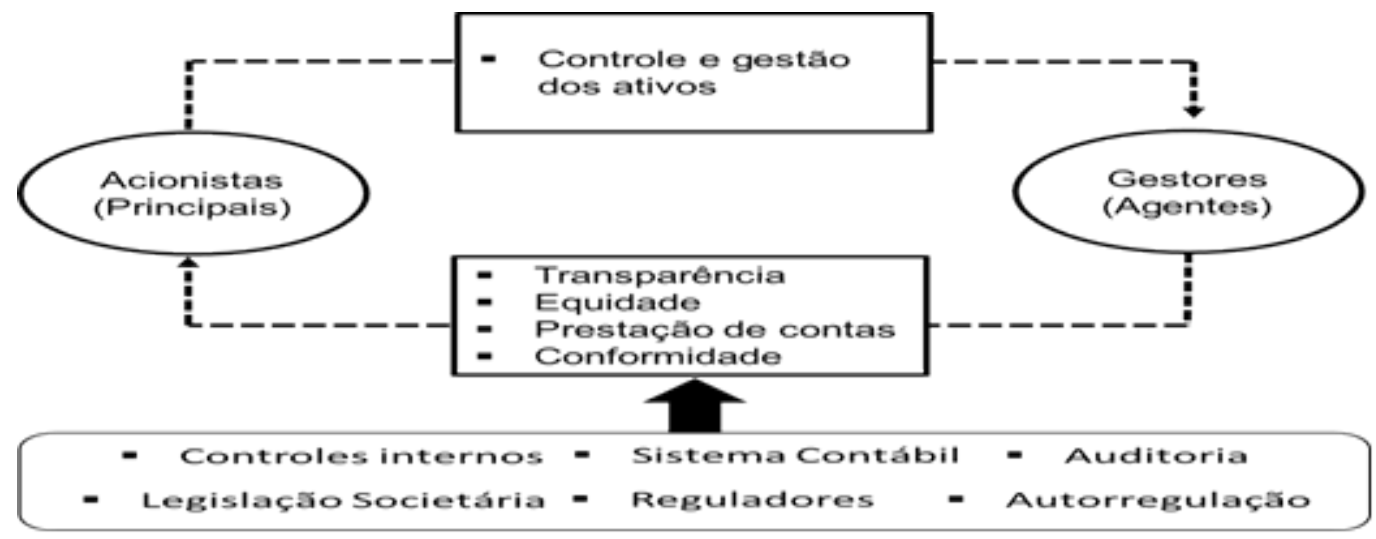

Figura 1. Relação de Agência e Princípios de Governança Fonte: Elaborado a partir de Brickley \& Zimmerman (2010), Di Pietra e Ronen (2014). 
Nesse contexto, Ramanan (2014) observa ainda que a auditoria assume importante papel na estrutura de governança das empresas. A Auditoria Interna busca reduzir os riscos relativos aos processos críticos, estruturando, revisando e monitorando o devido cumprimento dos controles internos e políticas definidas pelas empresas, buscando mitigar a ocorrência de erros e fraudes. A Auditoria Externa tem como objetivo avaliar a adequação das demonstrações contábeis a serem divulgadas ao mercado.

$\mathrm{O}$ ambiente regulatório que engloba as leis e normas estatuídas por reguladores com poder de polícia sobre os agentes econômicos têm papel essencial como instrumento de governança, pois elas estabelecem as regras e restrições a que estão sujeitos os diversos agentes econômicos, bem como as punições passíveis quando das suas infrações. O ambiente regulatório e o poder de enforcement das normas tem demonstrado consistentemente serem relevantes para a melhoria do ambiente de negócios, qualidade da informação contábil e, inclusive, as republicações (Pfarre, Smith, Bartol, Khanin \& Zhang, 2008; Khanin \& Mahto, 2012).

Por fim, o mercado por si busca mecanismos de maior eficiência e diferenciação entre os agentes econômicos. Nesse sentido, os esforços dos diversos participantes do mercado no sentido de melhor se relacionarem com as diversas partes interessadas tem sido intensos. No Brasil, desde a década de 1990, instituições privadas sem fins lucrativos têm buscado estimular a melhoria da transparência das empresas.

O Instituto Brasileiro de Governança Corporativa (IBGC), criado em 1995, por exemplo, desde 1999 publica o Código de Boas Práticas de Governança Corporativa. Esse movimento, estimulou em 2000 a criação dos Níveis Diferenciados de Governança das empresas que negociam ações na BM\&FBOVESPA. Trata-se de uma categorização de empresas listadas e que possuem práticas diferenciadas de Governança Corporativa. A BM\&FBOVESPA (2016) exige uma série de requisitos para listagem nos níveis diferenciados (Nível 1, Nível 2 e Novo Mercado) destacando-se: (i) emissão de ações ordinárias, (ii) circulação mínima de $25 \%$ das ações, (iii) estímulo à dispersão acionária, (iv) estímulo à dispersão acionária, (v) estímulo à independência do conselho, (vi) concessão de Tag Along.

\subsection{Hipóteses de gerenciamento de resultados}

O gerenciamento de resultados (earnings management) se refere à realização de escolhas contábeis (accounting choice) e operacionais que visam a atender a interesses específicos da firma (e/ou gestor). Segundo Defond (2010), o crescimento dos estudos sobre qualidade dos lucros (resultados) se fundamenta em questões como: (1) duras acusações pela SEC quanto ao gerenciamento de resultados; (2) acusações de ações oportunistas dos gestores de companhias abertas; (3) críticas quanto a possível conivência dos auditores com o gerenciamento resultados; (4) as recorrente fraudes contábeis observadas, como o caso Enron e ainda; a (5) mudança do ambiente normativo, tais como a SOX e mais recentemente, as IFRS.

Trata-se de um evento com origem no conflito de agência e visa atender a objetivos dos agentes e/ ou da firma, possuindo diversas motivações fundamentadas em três hipóteses principais: (1) oportunismo dos agentes, (2) nível de endividamento e (3) custos políticos (Dechow, Ge, \& Schrand, 2010).

\subsubsection{Oportunismo dos agentes}

O oportunismo ocorre quando os agentes utilizam da assimetria informacional para atender aos seus objetivos em detrimento aos dos acionistas (principais). Fields, Lys \& Vincent (2001) observam que, apesar de as escolhas contábeis decorrerem do exercício do julgamento na aplicação das normas de contabilidade, o interesse do gestor em afetar positivamente o resultado do exercício pode ser um dos motivos de sua ocorrência. De acordo com Bergtresser e Philipon (2006), o oportunismo dos agentes tem como motivações principais o interesse do gestor em maximizar seu pacote de remuneração, seja por meio do bônus por desempenho ou pelo exercício de opções e ações sob seu controle. Dessa relação surge a primeira hipótese de pesquisa ( do estudo: 
$\mathrm{H}_{1}=\mathrm{A}$ remuneração dos gestores afeta positivamente a republicação das demonstrações.

Como os gestores tendem a buscar maximizar seu bem-estar, existe o potencial de gerenciamento de resultados com essa finalidade. Elayan, Li e Meyer (2008) argumentam que as republicações são um evento negativo importante nas empresas e estão associadas ao gerenciamento de resultados, por vezes, incentivado pelo oportunismo dos agentes, interessados em maximizar seu pacote de remuneração. Evidências de que esse evento ocorre tem sido observado sistematicamente em estudos como os de Masulis, Wang \& Xie (2012), Dao, Huang, Chen e Huang (2014), Collins, Masli, Reitega \& Sanchez (2015), Lin, Lee, Chen e YurAustin (2015), Khalil e Ozkan (2016).

\subsubsection{Hipótese do nível de endividamento}

O nível de endividamento é um indicador de risco e oportunidade de crescimento da firma (Myers \& Majluf, 1984). A despeito de as dívidas terem um custo de capital inferior ao capital próprio e potencializar a maximização de valor, existe um limite aceitável desse nível de endividamento (Modigliani \& Miller, 1963; Myers \& Majluf, 1984). Nesse contexto, os agentes (e as empresas) estarão preocupados com essa métrica. Graham, Harvey \& Rajgopal (2005) destacam que 26,5\% dos executivos acreditam que o nível de endividamento é um forte incentivo para o gerenciamento de resultados.

Primeiro, porque o aumento do nível de endividamento pode acarretar em violação de cláusulas restritivas (debt covenants); segundo, que a elevação desse indicador pode prejudicar a avaliação de risco (credit risk) e, por conseguinte, aumentar o custo de capital, restringir o acesso a outras linhas de financiamento, entre outras implicações. Terceiro, porque essa motivação está fortemente associada à reputação e desempenho do gestor, e por conseguinte, seu pacote de incentivos e oportunidades de carreira. A partir desse contexto, analisou-se a segunda hipótese de pesquisa (da pesquisa:

$\mathrm{H}_{2}=\mathrm{O}$ nível de endividamento das empresas afeta positivamente a republicação das demonstrações.

De acordo com Mayers \& Majulf (1984), o endividamento, além do menor custo, sinaliza ao mercado sobre oportunidade de investimentos, além de receber influência de membros externos na estrutura de governança em decorrência de cláusulas restritivas. Por outro lado, ele pode aumentar o risco percebido pelo mercado e gerar efeitos adversos, tais como o aumento do custo de capital e risco de falência, por exemplo. Esses efeitos, por sua vez, podem ser motivos para gerenciamento de resultados. Estudos anteriores como os de Bardos (2011), Badertscher, Collins e Lys (2012), Chen, Cheng \& Lo (2013), Dao et al. (2014) e Baber, Kang, Liang e Zhu (2015) têm demonstrado que empresas mais endividadas tendem a ter maiores níveis de republicação.

\subsubsection{Hipótese dos Custos Políticos}

De acordo com Watts e Zimmerman (1978), os custos políticos referem-se à possibilidade de expropriação em uma das partes e decorrência da visibilidade da companhia, seja perante os reguladores, competidores e outras partes interessadas. De acordo com Key (1997), na Teoria dos Custos Políticos, na medida em que uma empresa está sujeita a potencial de transferência de riqueza para partes interessadas (processo político), os agentes estarão propensos a fazer escolhas contábeis que reduzam essa transferência. Trata-se de uma preocupação dos agentes com a visibilidade da firma perante os analistas, investidores institucionais, reguladores, do Fisco, dos concorrentes e outras partes interessadas (como os sindicatos por exemplo). 
A implicação dessa teoria é que as empresas com maior visibilidade estarão mais sujeitas a incorrerem em custos políticos, seja por necessidade de aumento da remuneração dos empregados, pagamento de tributos decorrentes de autuações fiscais/tributárias ou ainda aumento do custo de capital e redução do valor das ações decorrentes da maior percepção de risco (Dechow, Ge, \& Schrand, 2010; Graham, Harvey, \& Rajgopal, 2005; Tan, 2013; Nelson \& Skinner, 2013; Beatty \& Liao, 2014). Nesse contexto, os gestores buscarão apresentar um resultado que: (1) seja relativamente homogêneo, (2) atenda às expectativas do mercado; (3) não se diferencie excessivamente das demais empresas do setor. Nessa perspectiva, testou-se a terceira hipótese ( deste estudo:

$$
\mathrm{H}_{3}=\mathrm{O} \text { tamanho das empresas afeta positivamente a republicação das demonstrações. }
$$

Estudos que consideraram o efeito tamanho sobre as republicações têm demonstrado que, devido às grandes empresas estarem mais suscetíveis ao risco de fraudes e erros, elas tendem a republicarem mais as demonstrações contábeis (Ettrede, Scholz, Smith \& Sun, 2010; Alexander, Baugruss, Bernili, Lee \& Westberg, 2013). Ocorre que essas republicações têm efeitos adversos relevantes sobre o valor de mercado, custo de capital e reputação da empresa (Cao, Myers, \& Omer, 2012; Palmrose, Richardson, \& Scholz, 2004), logo, elas envidarão esforços para mitigarem esses riscos, pois os custos para a reconstrução da reputação são maiores, inclusive para os auditores (Kryzanowski \& Zhang, 2013; Francis, Michas e Yu, 2013). Entretanto, as evidências encontradas sustentam de forma mais persistente que quanto maior as empresas, maior será a probabilidade de republicação (Schrand \& Zechman, 2012; Chen, Cheng \& Lo, 2013; Cao, Feroz \& Davalos, 2015; Agrawal \& Copper, 2015; Baber et al., 2015).

\subsection{Reapresentação das Demonstrações Contábeis: conceitos e implicações}

A reapresentação consiste no ato de corrigir o reconhecimento, mensuração ou divulgação de dado que altere significativamente a avaliação e interpretação dos usuários externos, reduzindo o risco de seleção adversa por parte deles. Essa alteração pode decorrer de mudança intencional e adequada de política contábil, ou ainda por erro ou fraude, identificada a posteriori, demandando retificação das informações divulgadas (Marques, 2016).

Elayan et al. (2013) afirmam que as reapresentações estão associadas a irregularidades contábeis e que consumiram milhões de dólares nos últimos anos em decorrência dos riscos de litígio, reputação e expropriação. Entretanto, não se restringe a isso, pois as republicações podem decorrer inclusive de motivações qualitativas, para correção de dados relativos às notas explicativas, relatórios de administração, entre outras (Hellou Netto \& Pereira, 2010). Marques (2016) complementa que as republicações podem ser obrigatórias ou espontâneas. As obrigatórias ocorrem quando o regulador ou parte interessada (auditor, por exemplo) exige a republicação das informações divulgadas. As espontâneas são aquelas realizadas por vontade da empresa e não decorrem de imposição normativa ou contratual. Observa o autor que a maioria das demonstrações republicadas no Brasil são espontâneas (83\%) e que 73\% das republicações são para corrigir dados qualitativos.

Burks (2010), ao analisar dados do Government Accountability Office (GAO), do período de 1997 2005 de empresas Norte-Americanas, concluiu que o reconhecimento, a divulgação e a mensuração de eventos relativos a receitas, custos, ativos, seguros e reclassificações respondem por $75 \%$ das republicações realizadas no período.

No Brasil, não se têm estudos com essa amplitude, em grande medida porque os bancos de dados disponíveis com informações sobre republicações não apresentam um nível de detalhamento que possibilite tal levantamento. Entretanto, algum esforço científico tem sido realizado nesse sentido. 
Dantas, Chaves, Silva e Carvalho (2011, p. 57) realizaram uma análise de 65 republicações por determinação da CVM ocorridas no período de 2001 a 2009 e agruparam as motivações em: (1) Reconhecimento e mensuração de ativos e passivos (45,4\%); (2) Deficiência no processo de divulgação (disclosure) das notas explicativas (39\%); (3) Reconhecimento e mensuração de receitas e despesas (7,8\%); e (4) Outros $(7,8 \%)$. Esses resultados caminham no mesmo sentido dos trabalhos internacionais no que concerne às motivações de republicações obrigatórias, pois problemas de mensuração de itens patrimoniais e de resultados respondem por mais de 50\% dos motivos nos últimos tempos (Collins et al., 2015).

A republicação pode gerar implicações empíricas relevantes. De um lado trata-se de uma proxy de maior (ou menor) qualidade da informação contábil com os problemas associados (Dechow, Ge, \& Schrand, 2010). Por exemplo, Cao, Myers \& Omer (2012) destacam que as republicações têm efeito nefasto sobre a reputação empresarial, podendo reduzir o valor da empresa, aumentar o custo do capital, iniciar processos de execução e falência, entre outros. Chen, Elder \& Hung (2014) destacam que a o mercado reage negativamente às republicações, fazendo com que informações posteriores divulgadas pelas empresas percam credibilidade. Nessa perspectiva, alguns estudos foram realizados no contexto brasileiro, porém, com relativa escassez (Murcia \& Carvalho, 2007).

Entre os poucos identificados, Helou Netto \& Pereira (2010) buscaram analisar o efeito das republicações sobre o valor de mercado. Para tanto, analisaram 197 republicações de 24 empresas listadas na BM\&FBOVESPA ao longo de 2001 a 2009. Os resultados evidenciaram que as republicações por exigência tiveram efeito positivo sobre o valor da empresa, sugerindo que o mercado brasileiro recebe positivamente a retificação quando é obrigatória. Por outro lado, as demais motivações não afetaram significativamente os preços, sugerindo irrelevância informacional das republicações espontâneas, por exemplo.

Cunha, Magro \& Fernandes (2015) realizaram um estudo sobre o efeito das republicações no Gerenciamento de Resultados. Os autores analisaram dados de 40 republicações ocorridas no período de 1999 a 2012. Os resultados demonstraram que a republicação tem efeito negativo sobre as acumulações discricionárias, o que é coerente com a literatura da área. A republicação obrigatória decorre de exigência do regulador. Por vezes, essa exigência busca corrigir problemas relacionados ao reconhecimento de ativos, passivos e resultados (Dantas et al., 2011; Collins et al., 2015). Isso implica que, havendo uma republicação obrigatória, o órgão exigirá que se retifique potencial evento associado às acumulações discricionárias, já que o agente tenderá a gerenciar resultados (para cima ou para baixo). O regulador, por sua vez, exigirá que se reverta o procedimento adotado anteriormente, implicando no resultado encontrado por Cunha, Magro \& Fernandes (2015).

\section{Delineamento da pesquisa}

No presente estudo buscou-se apresentar informações sobre as republicações ao longo do período de 1998 a 2014. A amostra foi composta por 344 empresas listadas na BM\&FBOVESPA distribuídas nos segmentos de listagem da seguinte forma: 25 no Nível 1, 15 no Nível 2, 109 no Novo mercado e 195 no segmento Tradicional. Os dados foram coletados nos sítios da CVM e da BM\&FBOVESPA.

\subsection{Modelos e variáveis}

A análise das hipóteses utilizou a regressão com dados em painel. Os modelos com dados em painel são adequados para se reduzir os efeitos e/ou problemas econométricos, como a heterogeneidade individual, além aumentar os graus de liberdade e possibilitar inferências mais robustas (Fávero L. , 2013). No presente estudo, utilizaram-se duas especificações. A primeira, logística, em que a probabilidade de se republicar $[\mathrm{P}(\mathrm{repub})]$ foi função do Remuneração dos Gestores, Nível de Endividamento, Tamanho da empresa e das Variáveis de Controle, $f$ (RemGes, NivEnd, Tam, Variáveis de Controle). O Quadro 1 apresenta operacionalização das variáveis e os sinais esperados em cada coeficiente. 
Quadro 1:

Descrição das Variáveis

\begin{tabular}{|c|c|c|c|}
\hline Variável & $\begin{array}{c}\text { Sinal } \\
\text { Esperado }\end{array}$ & Sigla & Operacionalização \\
\hline Taxa de Republicação Acumulada & & TRA & $\begin{array}{l}\text { Total de Republicações Acumuladas até o ano t/Total } \\
\text { de Publicações Obrigatórias até o ano t. }\end{array}$ \\
\hline Republicação & & Repub & $\begin{array}{l}\text { Variável dummy que assume valor } 1 \text { quando houver } \\
\text { republicação da demonstração e zero quando não. }\end{array}$ \\
\hline Republicação Obrigatória & + & RepObrig & $\begin{array}{l}\text { Variável dummy que assume valor } 1 \text { quando houver } \\
\text { republicação obrigatória da demonstração e zero } \\
\text { quando espontânea. }\end{array}$ \\
\hline Remuneração Total dos Gestores & + & RemTot & $\begin{array}{l}\text { Logaritmo da razão entre a Remuneração dos } \\
\text { gestores no ano t pela Remuneração do ano } \\
\text { imediatamente anterior (t-1) }\end{array}$ \\
\hline Remuneração dos Diretores & + & RemDir & $\begin{array}{l}\text { Logaritmo da razão entre a Remuneração dos } \\
\text { Diretores no ano t pela Remuneração do ano } \\
\text { imediatamente anterior (t-1) }\end{array}$ \\
\hline Remuneração dos Conselho Fiscal & + & RemCFisc & $\begin{array}{l}\text { Logaritmo da razão entre a Remuneração dos } \\
\text { Membros do Conselho Fiscal no ano t pela } \\
\text { Remuneração do ano imediatamente anterior (t-1) }\end{array}$ \\
\hline Nível de Endividamento & + & NivEnd & Total de Passivo dividido pelo Ativo Total \\
\hline Tamanho & + & Ativo & Logaritmo do total do Ativo da empresa i no ano $t$ \\
\hline Crescimento do Ativo & + & CrescAt & $\begin{array}{l}\text { Logaritmo do total do ativo atual/total do ativo } \\
\text { anterior }\end{array}$ \\
\hline Retorno sobre os Ativos & - & ROA & Razão entre o EBIT/Ativo Total \\
\hline $\begin{array}{l}\text { Taxa de Republicação Acumulada } \\
\text { anterior }\end{array}$ & + & & $\begin{array}{l}\text { Total de Republicações Acumuladas até o ano t-1/ } \\
\text { Total de Publicações Obrigatórias até o ano t-1 }\end{array}$ \\
\hline Taxa de Republicação Obrigatória & + & & $\begin{array}{l}\text { Total de Republicações Obrigatória até o ano t/Total } \\
\text { de Republicações Obrigatórias até o ano t }\end{array}$ \\
\hline Accruals Totais & + & AT & $\begin{array}{l}\text { [(Ativo Circulante Operacional - Passivo Circulante } \\
\text { Operacional) - Depreciação] /Ativo Total (t-1)] }\end{array}$ \\
\hline Coeficiente de Variação do Lucro & + & CVEbit & $\begin{array}{l}\text { Coeficiente de Variação do EBIT até o ano t da } \\
\text { empresa i }\end{array}$ \\
\hline Retorno das Ações & + & $\mathrm{Ri}$ & $\begin{array}{l}\text { Logaritmo do ) em que é a média do preço da ação } \\
\text { nos três meses subsequentes a publicação da } \\
\text { demonstração e é a média do preço das ação nos } \\
\text { três meses anteriores à publicação }\end{array}$ \\
\hline Segmento Econômico & $+/-$ & SegEcon & $\begin{array}{l}\text { Variável dummy que assume valor } 1 \text { para o iésimo } \\
\text { setor, } 0 \text { para os demais }\end{array}$ \\
\hline Nível de Governança & - & NivGov & $\begin{array}{l}\text { Variável dummy que assume valor } 1 \text { para Nível de } \\
\text { Governança (N1, N2 ou NM), } 0 \text { para tradicional }\end{array}$ \\
\hline Sarbanes-Oxley & - & sox & $\begin{array}{l}\text { Variável dummy que assume valor } 1 \text { para o ano de } \\
\text { início de vigência da SOX, } 0 \text { para os demais. }\end{array}$ \\
\hline $\begin{array}{l}\text { International Financial Report } \\
\text { Standards Parcial }\end{array}$ & - & IFRS Parcial & $\begin{array}{l}\text { Variável dummy que assume valor } 1 \text { para o ano de } \\
\text { início de vigência do IFRS Parcial } 0 \text { para os demais. }\end{array}$ \\
\hline $\begin{array}{l}\text { International Financial Report } \\
\text { Standards Full }\end{array}$ & - & IFRS Full & $\begin{array}{l}\text { Variável dummy que assume valor } 1 \text { para o ano de } \\
\text { início de vigência do IFRS Full, } 0 \text { para os demais. }\end{array}$ \\
\hline Big Four & + & Big4 & $\begin{array}{l}\text { Variável dummy que assume valor } 1 \text { para empresas } \\
\text { auditadas por uma Big4, } 0 \text { para os demais. }\end{array}$ \\
\hline
\end{tabular}

Fonte: Elaborado a partir de Bardos (2011); Badertscher, Collins e Lys (2012); Masulis, Sing \& Xie (2012); Schrand \& Zechman, (2012); Chen, Cheng \& Lo (2013); Dao et al. (2014), Baber et al., (2015); Collins et al., (2015); Cao et al., (2015); Agrawal \& Copper (2015); Lin et al. (2015) Khalil e Ozkan (2016), Marques (2016). 
A estimação do modelo foi realizada por Máxima Verossilimilhança. Pindyck e Rubinfeld (2004) afirmam que quando se utiliza um modelo logit ou probit essa técnica é a mais adequada. A interpretação consiste em analisar o efeito marginal das variáveis explicativas sobre a probabilidade de chances de se observar a variável explicada (Wooldridge, 2010). Logo, analisou-se qual o efeito da Remuneração dos Gestores (RemTot, RemGes e RemCFisc), do Nível de Endividamento e do Tamanho da Empresa sobre a probabilidade de se republicarem as demonstrações contábeis (Repub). Além dessas variáveis que operacionalizam o teste das hipóteses avaliadas no estudo, utilizaram-se variáveis de controle, que têm sido, sistematicamente, identificadas na literatura como com efeitos significativos sobre o gerenciamento de resultados em outras proxies (Bardos, 2011; Badertscher, Collins e Lys, 2012; Masulis, Sing \& Xie, 2012; Schrand \& Zechman, 2012; Chen, Cheng \& Lo, 2013; Dao et al., 2014, Baber et al., 2015; Collins et al., 2015; Cao et al., 2015; Agrawal \& Copper, 2015; Lin et al., 2015; Khalil e Ozkan, 2016, Marques, 2016).

Para a avaliação da significância, estatística considerou-se um nível máximo de 10\%, logo, estatísticas z com p-valores iguais ou inferiores a $10 \%$ foram considerados significativos, valores comumente aceitos na área de Contabilidade (Fávero, Belfiore, Lopes da Silva, \& Chan, 2009). O Modelo inicial testado foi definido por (Equação 1):

$$
\begin{aligned}
& \mathrm{P}\left(\text { Repub }_{\mathrm{it}}=\beta_{0}+\beta_{1} \text { RemTot }_{\mathrm{it}}+\beta_{2} \text { Remdir }_{\text {it }}+\beta_{3} \text { RemCFisc }_{\mathrm{it}}+\beta_{4} \text { NivEnd }_{\mathrm{it}}+\beta_{5} \mathrm{Tam}_{\mathrm{it}}+\right. \\
& \beta_{6} \text { ROA }_{i t}+\beta_{7} \text { AT }_{i t}+\beta_{8} \text { CVEbit }_{i t}+\beta_{10} \text { TRA }_{\mathrm{it}-1}+ \\
& \beta_{9} \mathrm{Ri}_{\mathrm{it}}+D_{1} \text { SegEcon }_{i t}+D_{2} \text { NivGov }_{i t}+D_{3} \text { SOX }_{i t}+D_{4} \text { IFRS }_{i t}+D_{5} \text { Big }_{i t}+\varepsilon_{i t}
\end{aligned}
$$

Adicionalmente, realizou-se um teste de robustez, utilizando-se como variável explicativa a Taxa de Republicação Acumulada (Equação 2). Trata-se de um índice calculado a partir do total de republicações acumuladas até o ano" t" dividido pelo total de publicações a que estava obrigada a empresa a publicar até o ano "t." É uma medida relativa utilizada por Marques (2016) e tem uma tendência de decréscimo, já que se espera que as republicações sejam eventos isolados e não recorrentes.

$$
\begin{aligned}
& \mathrm{TRA}_{\mathrm{it}}=\beta_{0}+\beta_{1} \text { RemTot }_{\mathrm{it}}+\beta_{2} \text { Remdir }_{i \mathrm{t}}+\beta_{3} \text { RemCFisc }_{\mathrm{it}}+\beta_{4} \text { NivEnd }_{\mathrm{it}}+\beta_{5} \text { Tam }_{\mathrm{it}}+\beta_{6} \text { ROA }_{i t}+ \\
& \beta_{7} \text { AT } i t+\beta_{8} \text { CVEbit }_{i t}+\beta_{10} \mathrm{TRA}_{\mathrm{it}-1}+ \\
& \beta_{9} \mathrm{Ri}_{\mathrm{it}}+D_{1} \text { SegEcon }_{i t}+D_{2} \text { NivGov }_{i t}+D_{3} \text { SOX }_{i t}+D_{4} \text { IFRS }_{i t}+D_{5} \text { Big }_{i t}+\varepsilon_{i t}
\end{aligned}
$$

A interpretação dos dados utilizou o parâmetro de significância, entretanto, a interpretação consiste, nesse caso, em analisar o efeito marginal das variáveis explicativas sobre a TRA, que é um percentual. Logo, o aumento de $1 \%$ no ROA implicará um aumento de $\mathrm{X}$ pontos percentuais na TRA.

\subsection{Testes de diferenças entre as médias e medianas}

Os testes de diferenças entre as médias e medianas foram úteis para se avaliar a existência de diferenças estatísticas entre os períodos Pré e Pós IFRS. Como se tratam períodos normativos distintos, a comparação das médias entre ambos se justifica. Para tanto, utilizaram os testes T, Wilcoxon e Kruskall Wallis. Tratam-se de testes paramétricos e não paramétricos úteis para a comparação entre grupos com características distintas (Fávero et al., 2009; Manly, 2008). A hipótese nula avaliada no teste "t" consistiu em . A regra de decisão consistiu em rejeitar quando o p-valor for igual ou inferior a 10\%. Já a hipótese nula avaliada nos testes Wilcoxon e Kruskall Wallis consistiu em . Diante disso, quando o p-valor for igual ou inferior a $10 \%$ rejeita-se . 


\section{Analise e interpretação dos resultados}

\subsection{Estatística descritiva}

Inicialmente analisaram os principais aspectos da estatística descritiva (Tabela 1). Nesse aspecto, considerando a separação entre o período Pré e Pós cabe destacar as mudanças observadas nas variáveis em termos de homogeneidade. Observou-se que o Coeficiente de Variação $(\mu / \sigma)$ reduziu em todas as variáveis contábeis, exceto, o Retorno (LnRi) e os Accruals Totais. Esse resultado, por um lado apresenta indícios de melhor qualidade dos dados para fins de estudos quantitativos, pois a menor dispersão contribui principalmente para a realização de estimativas. Por outro lado, apresenta indícios de maior conservadorismo em se tratando dos Accruals Totais e maiores incertezas percebidas pelo mercado quando se observa o retorno das ações. Em termos gerais, observa-se que as variáveis utilizadas apresentaram aumento na maioria dos casos. Esse aumento tem interpretações diversas, pois o aumento do nível de endividamento, por exemplo, pode-se entender como um indicativo ruim a priori (Hutton, Marcus, \& Teharanian, 2009), porém, positivamente, pode evidenciar um aumento das oportunidades de investimentos (Myers \& Majluf, 1984).

Tabela 1:

\section{Estatística descritiva das variáveis dos modelos}

\begin{tabular}{|c|c|c|c|c|c|c|c|c|c|c|c|c|c|c|c|}
\hline & \multicolumn{6}{|c|}{ Pré IFRS } & \multicolumn{6}{|c|}{ Pós IFRS } & \multirow{2}{*}{$\begin{array}{c}\text { Teste } \mathbf{t} \\
\mathrm{t}(\text { Prob }>\mathrm{t})\end{array}$} & \multirow{2}{*}{$\begin{array}{l}\text { Wilcoxon } \\
z(\text { Prob }>z)\end{array}$} & \multirow{2}{*}{$\begin{array}{c}\begin{array}{c}\text { Kruskal } \\
\text { Wallis }\end{array} \\
\mathrm{x}^{2} \text { (Prob F) }\end{array}$} \\
\hline & $\mathrm{n}$ & $\mu$ & $\mathrm{s}$ & $\mathrm{CV}$ & $10 . Q$ & $30 . Q$ & $\mathrm{n}$ & $\mu$ & $\mathrm{s}$ & $\mathrm{CV}$ & 10.Q & 3o.Q & & & \\
\hline \multicolumn{16}{|c|}{ Painel A - Variáveis quantitativas } \\
\hline TRA & 3.367 & 0,12 & 0,21 & 1,74 & 0,00 & 0,20 & 2.432 & 0,27 & 0,23 & 0,87 & 0,08 & 0,39 & $-24,8059 *$ & $-32,028^{*}$ & $931,727 *$ \\
\hline TRA $_{1}$ & 3.367 & 0,09 & 0,26 & 2,88 & 0,00 & 0,00 & 2.443 & 0,26 & 0,23 & 0,91 & 0,08 & 0,38 & $-24,5356^{*}$ & $-31,072^{*}$ & $867,497 *$ \\
\hline LnNivEnd & 1.760 & $-1,13$ & 1,19 & $-1,06$ & $-1,38$ & $-0,43$ & 1.984 & $-1,27$ & 1,36 & $-1,08$ & $-1,57$ & $-0,46$ & $3,0188^{*}$ & $2,673^{*}$ & $7,144^{*}$ \\
\hline LnAtivo & 3.367 & 8,87 & 6,45 & 0,73 & 0,00 & 13,87 & 2.415 & 12,86 & 4,15 & 0,32 & 12,31 & 15,03 & $-28,5671 *$ & $-25,640^{*}$ & $650,925^{*}$ \\
\hline LnRemTot & & & & & & & 1.717 & 12,75 & 5,77 & 0,45 & 13,44 & 16,09 & & & \\
\hline LnRemDir & & & & & & & 1.717 & 11,38 & 6,69 & 0,59 & 8,88 & 15,91 & & & \\
\hline LnRemCFisc & & & & & & & 1.717 & 10,37 & 5,66 & 0,55 & 10,20 & 14,09 & & & \\
\hline LnRi & 3367 & 0,09 & 0,43 & 4,78 & 0,00 & 0,00 & 2.415 & $-0,00$ & 0,22 & $-100,44$ & $-0,02$ & 16,09 & $10,8097^{*}$ & $9,820 *$ & $82,872^{*}$ \\
\hline $\begin{array}{l}\text { Accruals } \\
\text { Totais }\end{array}$ & 3367 & $-0,12$ & 3,00 & $-25,64$ & $-0,05$ & 0,00 & 2.415 & $-0,04$ & 5,34 & $-123,23$ & $-0,09$ & 0,02 & $-0,7060$ & $2,014 * *$ & $3,989 * *$ \\
\hline CrescAtivo & 3.367 & 0,09 & 0,71 & 8,01 & 0,00 & 0,10 & 2.415 & 0,11 & 0,80 & 7,01 & $-0,01$ & 0,16 & $-1,2104$ & $-7,392^{*}$ & $53,778^{*}$ \\
\hline $\mathrm{ROA}$ & 3.367 & $-1,89$ & 8,53 & $-4,51$ & 0,00 & 0,09 & 2.415 & $-2,84$ & 7,37 & $-2,59$ & 0,00 & 0,12 & $1,7707 * \star \star$ & $-9,786 *$ & $94,681 *$ \\
\hline CVEbit & 3.367 & 9,81 & 28,37 & 2,89 & 6,05 & 11,26 & 2.415 & 6,25 & 1,21 & 0,19 & 5,90 & 6,87 & $7.5577^{\star}$ & $26,705^{*}$ & $713,132 *$ \\
\hline \multicolumn{16}{|c|}{ Painel B - Variáveis qualitativas } \\
\hline Republic & 3.367 & 0,14 & 0,35 & 2,48 & 0,00 & 1,00 & 2.443 & 0,30 & 0,46 & 1,52 & 0,00 & 1,00 & & $-15,140^{*}$ & $112,729 *$ \\
\hline TipRes & 3.367 & 0,16 & 0,37 & 2,26 & 0,00 & 0,00 & 2.443 & 0,24 & 0,42 & 0,42 & 0,00 & 0,00 & & $-5,923^{*}$ & $16,809 *$ \\
\hline NivGov & 3.367 & 0,43 & 0,50 & 1,15 & 0,00 & 1,00 & 2.443 & 0,43 & 0,50 & 1,15 & 0,00 & 1,00 & & & \\
\hline SOX & 3.367 & 0,10 & 0,30 & 2,98 & 0,00 & 0,00 & 2.443 & & & & & & & & \\
\hline IFRS Full & & & & & & & 2.443 & 0,14 & 0,35 & 2,45 & 0,00 & 1,00 & & & \\
\hline Big4 & 3.367 & 0,39 & 0,49 & 1,26 & 0,00 & 1,00 & 2.443 & 0,65 & 0,48 & 0,73 & 0,00 & 1,00 & & $-19,348 *$ & $283,375^{*}$ \\
\hline
\end{tabular}

Nota: $*, \star \star, * \star \star$ - Diferença estatisticamente significativa ao nível de $1 \%, 5 \%$ e $10 \%$. Médias das variáveis qualitativas (Dummy) referem-se à proporção da característica que assume valor 1.

Legenda: TRA: Total de Republicações Acumuladas até o ano t/Total de Publicações Obrigatórias até o ano t.; Repub: Variável dummy que assume valor 1 quando houver republicação da demonstração e zero quando não; RepObr: Variável dummy que assume valor 1 quando houver republicação obrigatória da demonstração e zero quando espontânea; RemTot: Logaritmo da razão entre a Remuneração dos gestores no ano t pela Remuneração do ano imediatamente anterior (t-1); RemDir: Logaritmo da razão entre a Remuneração dos Diretores no ano t pela Remuneração do ano imediatamente anterior (t-1); RemFisc: Logaritmo da razão entre a Remuneração dos Membros do Conselho Fiscal no 
ano t pela Remuneração do ano imediatamente anterior (t-1); NivEnd: Passivo/Ativo; Tam: CrescAt: Logaritmo do total do ativo atual/total do ativo anterior; Ln(Ativo); ROA: Razão entre o EBIT/Ativo Total; Total de Republicações Obrigatória até o ano t/Total de Republicações Obrigatórias até o ano t; : Total de Republicações Obrigatória até o ano t/Total de Republicações Obrigatórias até o ano t; AT: [(Ativo Circulante Operacional - Passivo Circulante Operacional) - Depreciação] /Ativo Total (t-1)]; CVEbit: Coeficiente de Variação do EBIT até o ano t da empresa i: Ri: Logaritmo do ) em que é a média do preço da ação nos três meses subsequentes a publicação da demonstração e é a média do preço das ação nos três meses anteriores à publicação; SegEcon: Variável dummy que assume valor 1 para o iésimo setor, 0 para os demais; NivGov: Variável dummy que assume valor 1 para Nível de Governança (N1, N2 ou NM), 0 para tradicional; sox: Variável dummy que assume valor 1 para o ano de início de vigência da SOX, 0 para os demais. IFRS Parcial: Variável dummy que assume valor 1 para o ano de início de vigência do IFRS Parcial 0 para os demais. IFRS Full: Variável dummy que assume valor 1 para o ano de início de vigência do IFRS Full, 0 para os demais; Big4: Variável dummy que assume valor 1 para empresas auditadas por uma Big4, 0 para os demais.

Além disso, verifica-se que houve uma melhoria em alguns indicadores relevantes para a análise financeira, tais como: LnAtivos, CrescAtivo, ROA. Observou-se também redução em indicadores importantes para a mesma finalidade, destacando-se: LnRi, AccrualsTotais e CVEbit. No que se refere aos indicadores que sofreram aumento, tratam-se de parâmetros utilizados para a avaliação do potencial de geração de retorno das empresas, logo, seu aumento pode indicar um aumento desse potencial (Jiao, Kaning \& Roosenboom, 2012) -

Do mesmo modo, as variáveis que tiveram redução em suas médias, a rigor, são utilizadas pelo mercado em suas avaliações, porém, com interpretações opostas. No caso do retorno (LnRi), essa redução indica piora do desempenho dos preços das ações, o que pode gerar ajustes para baixo das expectativas dos investidores. Já em relação à redução dos Accruals (AccrualsTotais) e do Coeficiente de Variação do Lucro (CVEbit), o primeiro pode se relacionar a um conservadorismo no período Pós-IFRS (Abed, Al-Badainah, \& Serdaneh, 2012), que, por sua vez, tende a reduzir a variabilidade dos lucros, sugerindo o que se entende na literatura de Contabilidade e Finanças como Income Smoothing, uma das formas de se gerenciar resultados (André, Filip, \& Paugam, 2015). Por fim, verificou-se que as diferenças foram, estatisticamente, significativas, conforme os testes de diferenças entre as médias utilizados.

\subsection{Incentivos à republicação das demonstrações}

Inicialmente analisou-se o modelo logístico (1) para a avaliação do efeito das hipóteses de gerenciamento de resultados sobre a republicação (Tabela 2). No que se refere à Hipótese de Oportunismo dos Agentes ( observou-se que, de forma consistente, apenas a Remuneração da Diretoria apresentou (RemDir) significância estatística ao nível de $1 \%$. Entretanto, o sinal predito $[S(p)]$ foi negativo, evidenciando que o pacote de remuneração é um ótimo incentivo à melhoria da qualidade da informação contábil, no presente estudo, utilizando a proxy a republicação. Schrand \& Zechman (2012) identificaram relação positiva entre pacote de remuneração e as republicações, confirmando a hipótese de oportunismo dos agentes.

Entretanto, o pacote de incentivos é uma das estratégias das empresas para mitigarem os riscos de agência (Jensen \& Meckling, 1976). Porém, como os agentes possuem um desejo autorrenovável e insaciável, o risco pode permanecer (Jensen \& Meckling, 1994). Masulis, Wang \& Xie (2012) destacam que o esquema de compensação adequado pode desestimular os gestores a agirem oportunisticamente. Healy (1985) já recomendava a formulação de contratos de contratos que atingissem os objetivos dos principais, pois existe uma propensão dos agentes realizarem escolhas contábeis, considerando os pacotes de remuneração. Outro aspecto relevante e que fundamenta os resultados encontrados é que existe uma associação positiva entre republicação e o turnover de gestores, auditores externos - isso significa que existe o risco eminente de perdas em potencial desses agentes o que pode ser um fator de desestímulo à republicação (Kryzanowski \& Zhang, 2013; Collins et al., 2015). 
Tabela 2:

Modelo Logit (1) para Determinantes das Republicações das Demonstrações Contábeis

\begin{tabular}{|c|c|c|c|c|c|c|c|c|c|}
\hline \multirow{2}{*}{ P (Repub) } & \multicolumn{3}{|c|}{$1998-2014$} & \multicolumn{3}{|c|}{ 1998-2007 } & \multicolumn{3}{|c|}{$2008-2014$} \\
\hline & $S(P)$ & OR & $z$ & $S(P)$ & OR & $z$ & $S(P)$ & OR & z \\
\hline Intercepto & - & 0,0326 & $-5.00 *$ & - & 0,0460 & $-5.08 *$ & + & 0,0261 & $-9.36 *$ \\
\hline NivEnd & - & 0,9890 & -0.19 & + & 1,0884 & 1.22 & + & 1,1054 & 0.45 \\
\hline Tam & + & 1,1108 & $2.87 *$ & + & 1,1696 & $3.72 *$ & + & 1,1285 & $4.50 *$ \\
\hline RemTot & + & 1,0311 & 1.37 & & & & + & 1,0219 & 1.14 \\
\hline RemDir & - & 0,9619 & $-2,39 * \star$ & & & & - & 0,9698 & $-2.12^{\star \star}$ \\
\hline RemCFisc & + & 1,0245 & 1.23 & & & & + & 1,0074 & 0.42 \\
\hline Ri & + & 1,5747 & 1,45 & & & & + & 1,4955 & 1.48 \\
\hline Accruals Totais & & & & & & & - & 0,9815 & -1.53 \\
\hline CrescAtivo & + & 1,6956 & $1.80 * \star$ & + & 1,7495 & $2.31 * *$ & + & 1,0821 & 1.01 \\
\hline N1 & + & 1,5651 & $1.66^{\star \star \star}$ & - & 0,7942 & -0.84 & + & 1,5407 & $1.60 * \star \star$ \\
\hline SOX & & & & - & 0,5253 & $-2.56 * \star$ & & & \\
\hline IFRS Full & + & 5,8242 & $7.75^{\star}$ & & & & + & 5,0490 & $8.14^{*}$ \\
\hline Big4 & + & 1,5501 & $2.21 * \star$ & + & 1,2363 & 1.30 & + & 1,5252 & $2.47 * \star$ \\
\hline N.Obs./Grupos & \multicolumn{3}{|c|}{$1395 \mid 321$} & \multicolumn{3}{|c|}{$1760 \mid 247$} & \multicolumn{3}{|c|}{$1717 \mid 349$} \\
\hline Estat F(Prob > F)/Wald $\left(x^{2}\right)$ & \multicolumn{3}{|c|}{$116,82 \mid 0,0000$} & \multicolumn{3}{|c|}{$62,09 \mid 0,0000$} & \multicolumn{3}{|c|}{$127,88 \mid 0,0000$} \\
\hline
\end{tabular}

Nota: * $* \star, * \star *$ Estatisticamente significativo aos níveis de 1\%,5\% e 10\%. O teste Wooldridge evidenciou presença de autocorrelação e heterocedasticidade sendo usados os erros padrões robustos clusterizados na empresa. Utilizou-se o Modelo de Dados em Painel Logístico com Efeitos Aleatórios conforme as propriedades de ajustamento descritas por Fávero et al. (2009). No período de 1998-2007 observou-se um efeito negativo e estatisticamente significativo nos seguintes anos: $1998(|\mathrm{OR}| 0.2230158|\mathrm{z}|-3.89 *), 1999\left(|\mathrm{OR}| 0.5652443|\mathrm{z}|-2.13^{* *}\right), 2000$ ( |OR $0.3128625|z|$ $-4.01 *), 2001$ ( |OR $0.6217064|z|-1.89 * *), 2003(\mid$ OR | 0,416642 |z| -3.39*), $2004(\mid$ OR $|0.4150204| z \mid-3.45 *), 2005$ ( |OR $0.5989329|z|-2.14^{* *}$ ) e 2006 ( |OR | $\left.0.6672775|z|-1.75^{\star * *}\right)$. No período de 2008-2014 observou-se significância estatística nas dummies para os anos de 2011 (|OR| 2.404319 |z| 4.43*), 2012 (|OR| 2.059242 |z| 3,62*) e 2013 (|OR| $1.36857|z| 1,54 *)$. As demais variáveis foram omitidas por insignificância estatística. Exceto aquelas que se relacionavam diretamente com as hipóteses gerais de gerenciamento de resultados. Conforme orientações de Wooldridge (2010) foram mantidas as variáveis com estatística Z igual ou superior a 1, ainda que não apresentasse significância estatística ao nível de $1 \%, 5 \%$ e $10 \%$.

Legenda: Repub: Variável dummy que assume valor 1 quando houver republicação da demonstração e zero quando não; NivEnd: Passivo/Ativo; Tam:In(ativo do ativo total); RemTot: Logaritmo da razão entre a Remuneração dos gestores no ano t pela Remuneração do ano imediatamente anterior (t-1); RemDir: Logaritmo da razão entre a Remuneração dos Diretores no ano t pela Remuneração do ano imediatamente anterior (t-1); RemFisc: Logaritmo da razão entre a Remuneração dos Membros do Conselho Fiscal no ano t pela Remuneração do ano imediatamente anterior (t-1); Ri: Logaritmo do ) em que é a média do preço da ação nos três meses subsequentes a publicação da demonstração e é a média do preço das ação nos três meses anteriores à publicação; AT: [(Ativo Circulante Operacional - Passivo Circulante Operacional) - Depreciação] / Ativo Total (t-1)]; CrescAt: Logaritmo do total do ativo atual/total do ativo anterior; NivGov: Variável dummy que assume valor 1 para Nível de Governança (N1, N2 ou NM); ; SOX: Variável dummy que assume valor 1 para o ano de início de vigência da SOX, 0 para os demais. IFRS Full: Variável dummy que assume valor 1 para o ano de início de vigência do IFRS Full, 0 para os demais; Big4: Variável dummy que assume valor 1 para empresas auditadas por uma Big4, 0 para os demais.

A Hipótese de Endividamento ( afirma que empresas mais endividadas apresentam maior tendência a gerenciar resultados, seja para reduzir a percepção de risco ou evitar cláusulas restritivas. Logo, esperava-se que o nível de endividamento afetasse positivamente as republicações. No presente estudo, os resultados foram coerentes com a expectativa teórica no que se refere aos sinais esperados (Tan, 2013; Baber et al., 2015; Cao et al., 2015) entretanto, não foram estatisticamente significativas. De acordo com Jensen e Meckling (1976), se a empresa apresenta um maior nível de endividamento e, portanto, maior nível de risco percebido, ela pode ser incentivada pelo benefício da maior qualidade das informações prestadas, pois isso geraria um menor custo de capital (Bardos, 2011; Agrawal \& Cooper, 2015). Entretanto, no presente estudo, o nível de endividamento não apresentou significância estatística suficiente para suportar a teoria proposta. 
A última hipótese testada () foi a de que o Tamanho das empresas tem efeito positivo sobre a republicação (Elayan, LI, \& Meyer, 2008; Kryzanowski \& Zhang, 2013; Khalil \& Ozkan, 2016). Essa hipótese foi confirmada tanto no período Pré IFRS quanto pós IFRS. Isso significa que empresas maiores têm maior propensão à republicação. Entretanto, no contexto brasileiro há que se destacar que a maioria das republicações são do tipo "espontâneas", logo, não, necessariamente, se trata de aumento das irregularidades. Marques (2016) observa que o aumento das republicações, caso tratem-se de informações espontâneas e qualitativas, não significam necessariamente um problema. Tanto que Helou Netto \& Pereira (2010) observaram que, no mercado brasileiro, apenas as republicações obrigatórias geram efeito significativo no comportamento dos preços das ações. Na literatura estrangeira, a republicação gera comportamento adverso no mercado mais rapidamente, o que é esperado dado o nível de desenvolvimento do mercado de capitais, bem como os eventos de fraudes e erros das últimas duas décadas ( (Di Pietra, McLeay, \& Ronen, 2014).

O ambiente normativo tem relativa importância pesquisas em Contabilidade (Di Pietra, McLeay, \& Ronen, 2014), isso porque como a Contabilidade é fortemente influenciada pelo padrão normativo vigente, o estudo no campo sem considerar seu efeito pode viesar a análise. No presente estudo, realizou-se um recorte temporal nos dados em período Pré-IFRS (1998-2007) e Pós-IFRS (2008-2014). Essa separação foi necessária pelo fato de a maioria das variáveis serem de natureza contábil, isso implica que, como foram mensuradas a partir de padrões diferentes, a análise conjunta poderia viesar os resultados. Por outro lado, a separação possibilita visualizar mais adequadamente as diferenças entre os períodos.

Além disso, controlou-se o efeito da adoção de duas importantes normas para a contabilidade, a Sarbanes-Oxley (SOX) e as IFRS. A SOX estabeleceu regras mais rígidas de controles internos (Alexander et al., 2013). Já as IFRS consistem em um padrão de normas contábeis, a priori, de melhor qualidade (Dechow, Ge, \& Schrand, 2010). Os resultados demonstraram que a implementação da SOX gerou uma redução sobre a probabilidade de se republicar. Esse resultado reforça a importância da norma e dos mecanismos de governança (Kryzanowski \& Zhang, 2013; Chen, Elder, \& Hung, 2014), pois, como a SOX reforça a estrutura de controles internos e os instrumentos de Accountability, isso implica uma melhoria na qualidade da informação reportada reduzindo o volume de republicações.

Por outro lado, a adoção das Full IFRS apresentou efeito positivo e significativo. Esse resultado sinaliza para as preocupações aventadas por Ball (2006). Em sua perspectiva, as IFRS não necessariamente significam melhoria instantânea, pois aspectos culturais podem fazer com que as interpretações sejam diversas. Entretanto, como a maioria das republicações são espontâneas e por motivos qualitativos (Marques, 2016), esses achados podem decorrer de alterações e/ou correções que não afetam significativamente a qualidade das informações (Hellou Netto \& Pereira, 2010). Entretanto, chama a atenção dos reguladores para uma maior atenção sobre a continuidade da taxa de republicação.

Outra variável de controle avaliada foi o Crescimento dos Ativos (CrescAtivo) - sua utilização, assim como o ROA, se fundamenta na Hipótese dos Custos Políticos (Key, 1997). Primeiro que empresas com maiores taxas de crescimento estarão mais sujeitas a republicação (Young \& Peng, 2012; Baber et al., 2015). Por outro lado, as empresas com maiores desempenhos (ROA) terão incentivos para não republicarem (Cao, Myers, \& Omer, 2012; Chen, Elder, \& Hung, 2014; Masulis, Wang, \& Xie, 2012). Os resultados do estudo demonstraram exatamente o que se esperava. O crescimento dos ativos teve efeito positivo sobre a probabilidade de se republicar as demonstrações, logo, taxas de crescimentos mais acentuadas dos ativos indicam maior risco de manipulação e gerenciamento de resultados, o que afeta positivamente sobre a republicação. No caso do ROA, à medida que aumenta reduz a probabilidade de se republicar, o que é coerente com duas hipóteses de gerenciamento de resultados: a primeira, dos custos políticos e a segunda do oportunismo dos agentes, pois o aumento do ROA somente os estimulariam a gerenciar resultados, se, e somente se, o resultado corrente estiver além do esperado. Logo, poderia antecipar perdas para favorecer o pacote de remuneração futuro ou ainda homogeneizar o desempenho corrente (Tan, 2013; Beatty \& Liao, 2014). 
Por fim, controlou-se o efeito auditor. A auditoria tem papel representativo na estrutura de governança das empresas. Além disso, os estudos sobre gerenciamento de resultados têm reportado sistematicamente um efeito redução das Big Four sobre esse evento. Isso significa que a hipótese geral sobre o efeito das grandes firmas de auditoria é de que elas reduzam a probabilidade de republicação das demonstrações (Thompson \& McCoy, 2008). No presente estudo, os resultados refutaram a hipótese sobre o efeito das Big Four. O que se observou foi que elas têm efeito positivo e significativo sobre a probabilidade de republicação. A princípio parece incoerência teórica, entretanto, duas questões devem ser consideradas. Primeiro que existe uma concentração dessas empresas entre as empresas listadas isso pode fazer com que o crescimento das republicações se associem a esse tipo de auditor, entretanto, mesmo no período de adoção da SOX que houve redução das republicações, o resultado quanto aos auditores foi de aumento. Como tratam-se em sua maioria de republicações espontâneas (Marques, 2016), esses resultados podem sinalizar maior nível de transparência por parte das empresas (Cao, Myers, \& Omer, 2012).

\subsubsection{Teste de robustez}

De modo a se verificar a robustez dos resultados apresentados na Tabela 2, realizou-se análise do modelo anterior, entretanto, utilizando como variável explicativa a TRA - Taxa de Republicação Acumulada (Quadro 1). Os resultados (Tabela 3) demonstraram que o NivEnd, que não apresentou significância estatística no Mod.1, apresentou significância estatística negativa sobre a TRA, sugerindo que empresas mais endividadas tenderão a ter uma TRA menor. Esse resultado é coerente com a busca pela melhoria da reputação, implicando, por exemplo, a redução do custo de capital e maior acesso a fontes de financiamento de terceiros (Huber \& Bochner, 2012; Dao, Huang, Chen, \& Huang, 2014). Por sua vez, o Tam, variável que captura o efeito dos custos políticos sobre a republicação, manteve o sinal positivo, porém sem significância estatística.

Por fim, a remuneração total apresentou efeito positivo sobre a TRA, coerente com a hipótese de que existe uma associação positiva entre gerenciamento de resultados e o pacote de remuneração (Healy, 1985). Entretanto, duas questões devem ser observadas. O fato de tratar-se da proxy republicação, que, como já analisado por Marques (2016), no Brasil, em sua maioria referem-se a republicações qualitativas, logo, não necessariamente pode-se afirmar tratar-se de gerenciamento de resultados. Segundo que, como pode ser observado na Tabela 3, a remuneração do conselho fiscal apresentou sinal negativo, apesar de não ter significância estatística. Porém, isso, sinaliza que pode haver um efeito restrição do Conselho Fiscal sobre as chances de se republicar, o que converge com a proposta da teoria da Agência de que mecanismos de monitoramento e controle devem ser utilizados (Jensen \& Meckling, 1976).

Além disso, observou-se que SOX e o NivGov foram, estatisticamente, significativos e com efeito negativo evidenciando a melhoria da qualidade das demonstrações, utilizando-se a TRA como métrica de qualidade. Esses resultados reforçam a necessidade de se utilizarem mecanismos de governança e melhor estrutura de controles internos (Alexander, Bauguess, Bernile, Lee, \& Westberg, 2013; Brickley \& Zimmerman, 2010). Observou-se ainda que a TRA do período anterior tem efeito significativo e positivo sobre a TRA corrente, o que sugere que empresas com histórico de republicações tendem a terem maiores taxas, o que é coerente. Entretanto, como a TRA é um índice das Republicações e Publicações acumuladas, espera-se que haja uma tendência natural do seu decréscimo o que foi evidenciado, observando-se os efeitos anuais no recorte 1998-2007 (vide nota abaixo da Tabela 3). Nesse contexto, o resultado sugere que existe uma associação entre o histórico de republicações e sua chance de republicar atualmente. Uma evidência importante e que não foi captada no modelo Logit (Mod.1) foi o efeito das republicações obrigatórias (RepObr). No Mod. 2 verificou-se que a RepObr, apesar de ser uma minoria (Marques, 2016), ela tem efeito positivo e estatisticamente significativa, o que atribui relevância a sua análise posterior. 
Por fim, verificou-se que ser auditado por uma Big4 aumenta a chance de republicação. Esse resultado pode estar associado à uma busca de maior transparência no mercado na medida em que a maioria das demonstrações republicadas são de natureza qualitativa (Marques, 2016). Por outro lado, pode tratar-se do efeito conjunto tamanho x Big4, já que empresas maiores terão maior propensão à republicação conforme observado.

Tabela 3:

Modelo (2) para Determinantes das Republicações das Demonstrações Contábeis

\begin{tabular}{|c|c|c|c|c|c|c|c|c|c|}
\hline \multirow{2}{*}{ TRA } & \multicolumn{3}{|c|}{ 1998-2014 } & \multicolumn{3}{|c|}{ 1998-2007 } & \multicolumn{3}{|c|}{$2008-2014$} \\
\hline & $S(P)$ & Coef. & z & $S(P)$ & Coef. & Z & $S(P)$ & Coef. & $\mathbf{Z}$ \\
\hline Intercepto & + & 0,2092 & $8,22 *$ & + & 0,1880 & $4.38 *$ & + & 0,2095 & 8.24 * \\
\hline NivEnd & - & 0,0099 & $-2.61 *$ & + & 0,0050 & 1.03 & - & 0,0098 & $-2.59 *$ \\
\hline Tam & + & 0,0007 & 0.58 & + & 0,0027 & 0.97 & + & 0,0007 & 0.58 \\
\hline RemTot & + & 0,0021 & $1.60 * * *$ & & & & + & 0,0021 & $1.60 * * *$ \\
\hline RemDir & - & 0,0000 & 0.04 & & & & + & 0,0000 & 0.03 \\
\hline RemCFisc & - & 0,0004 & 0.40 & & & & - & 0,0004 & -0.41 \\
\hline $\mathrm{Ri}$ & & & & - & 0,0130 & -1.59 & & & \\
\hline CresAtivo & & & & - & 0,0399 & $-2.69 *$ & & & \\
\hline CVEbit & & & & - & 0,0008 & -1.12 & & & \\
\hline TipRes & + & 0,0097 & 1.11 & + & .011858 & 1.08 & + & 0,0097 & 1.11 \\
\hline TRA-1 & + & 0,0351 & 1.30 & + & 0,1293 & $5.45 *$ & + & 0,0351 & 1.30 \\
\hline NivGov & - & 0,0492 & $-2.0 * \star$ & - & .0490802 & $-2.03^{* \star \star}$ & - & 0,0492 & $-2.00 * \star$ \\
\hline SOX & & & & - & .0757442 & $-5.11 *$ & & & \\
\hline IFRS Full & + & 0,0177 & $2.37 * \star$ & & & & + & 0,0177 & $2.37^{\star *}$ \\
\hline Big4 & + & 0,0336 & $2.73^{\star}$ & + & 0,0351 & $3.21 *$ & + & 0,0336 & $2.73 *$ \\
\hline RepObr & + & 0,0432 & $2,89 *$ & + & 0,0648 & $3.05^{*}$ & + & 0,0432 & $2.89 *$ \\
\hline N.Obs./Grupos & \multicolumn{3}{|c|}{1395 | 321} & \multicolumn{3}{|c|}{$1760 \mid 247$} & \multicolumn{3}{|c|}{1395 | 321} \\
\hline Estat F (Prob > F)/Wald $\left(x^{2}\right)$ & \multicolumn{3}{|c|}{$70.97 \mid 0.0000$} & \multicolumn{3}{|c|}{$178.06 \mid 0.0000$} & \multicolumn{3}{|c|}{$62.24 \mid 0.0000$} \\
\hline $\mathrm{R}^{2}$ (Entre, Dentre, Geral) & \multicolumn{3}{|c|}{$(5,65 \%|2,31 \%| 2,32 \%)$} & \multicolumn{3}{|c|}{$(8,45 \%|17,07 \%| 15,49 \%)$} & \multicolumn{3}{|c|}{$(5,65 \%|2,31 \%| 2,32 \%)$} \\
\hline Dummy para o ano & \multicolumn{3}{|l|}{ Sim } & \multicolumn{3}{|l|}{ Sim } & \multicolumn{3}{|l|}{ Sim } \\
\hline Dummy para o setor & \multicolumn{3}{|l|}{ Não } & \multicolumn{3}{|l|}{ Não } & \multicolumn{3}{|l|}{ Não } \\
\hline
\end{tabular}

Nota: ${ }^{*}, * \star, * \star *$ Estatisticamente significativo aos níveis de 1\%, 5\% e 10\%. O teste Wooldridge evidenciou presença de autocorrelação e heterocedasticidade sendo usados os erros padrões robustos clusterizados na empresa. Utilizou-se o Modelo de Dados em Painel com Efeitos Aleatórios realização dos testes de Chow, Breush-Pagan, Hausmann (Wooldridge, 2010). No período de 1998-2013 observou-se significância positiva e estatisticamente significativa nos seguintes anos: 2011 ( |Coef 0.0272001 |z| 3.71*), 2012 (|Coef| 0.0301007 |z| 4.16*) e 2013 (|Coef| 0.0220834 |z| 3.05*). No período de 1998-2007 observou-se um efeito negativo e estatisticamente significativo nos seguintes anos:, 1998 ( |Coef| -0.1235946 $|z|-6.33 *), 1999$ ( |Coef.| -0.0881512 |z| -5.18*), 2000 (|Coef| -0.0975112 |z| -6.08*), 2001 (|Coef.| -0.0938012|z| $\left.-6.12^{*}\right), 2003$ ( |Coef.| -0.0768859 |z| -5.25*), 2004 (|Coef.| -0.0762157 |z| -5.35*), 2005 (|Coef.| -0.0406388|z| -2.91*) e 2006 ( |Coef. | -0.0262708 |z| -1.94*). No período de 2008-2014 observou-se significância estatística positiva nos anos de 2011 (|Coef.| 0.0281561 |z| 3.84*), 2012 (|Coef.| 0.0312189|z| 4.31*) e 2013(|Coef.| 0.0219911 |z| 3.03*).

Legenda: TRA: Total de Republicações Acumuladas até o ano t/Total de Publicações Obrigatórias até o ano t.; NivEnd: Passivo/Ativo; Tam:In(ativo do ativo total); RemTot: Logaritmo da razão entre a Remuneração dos gestores no ano t pela Remuneração do ano imediatamente anterior (t-1); RemDir: Logaritmo da razão entre a Remuneração dos Diretores no ano t pela Remuneração do ano imediatamente anterior (t-1); RemFisc: Logaritmo da razão entre a Remuneração dos Membros do Conselho Fiscal no ano t pela Remuneração do ano imediatamente anterior (t-1); Ri: Logaritmo do ) em que é a média do preço da ação nos três meses subsequentes a publicação da demonstração e é a média do preço das ação nos três meses anteriores à publicação; AT: [(Ativo Circulante Operacional - Passivo Circulante Operacional) - Depreciação] / Ativo Total (t-1)]; CrescAt: Logaritmo do total do ativo atual/total do ativo anterior; NivGov: Variável dummy que assume valor 1 para Nível de Governança (N1, N2 ou NM); SOX: Variável dummy que assume valor 1 para o ano de início de vigência da SOX, 0 para os demais. IFRS Full: Variável dummy que assume valor 1 para o ano de início de vigência do IFRS Full, 0 para os demais; Big4: Variável dummy que assume valor 1 para empresas auditadas por uma Big4, 0 para os demais.

Fonte: Dados da pesquisa. 


\section{Considerações finais}

O presente estudo teve como objetivo verificar se o pacote de remuneração dos gestores, o nível de endividamento e o tamanho da empresa afetam a republicação das demonstrações financeiras. O estudo de natureza descritiva, documental e com abordagem quantitativa analisou dados de 344 empresas listadas na BM\&FBOVESPA no período de 1998 a 2014. Os dados foram analisados por meio da análise de regressão com dados em painel, utilizando-se dois modelos. No primeiro, com a variável explicativa binária (1 para Republicação e 0 para não), utilizou-se um modelo logístico multivariado. No segundo, como teste de robustez, utilizou-se uma variável quantitativa, denominada Taxa de Republicação Acumulada (TRA), como variável explicativa.

No modelo logístico, observou-se que o tamanho e o pacote de remuneração têm efeito positivo sobre a Republicação (Repub e TRA). Do mesmo modo, a adoção do IFRS e o fato de ser auditado pelas Big4 aumentam na razão de chances de se republicar. Entre as variáveis que reduzem essa probabilidade de republicação destacaram-se a SOX, o NivGov.

O teste de robustez confirmou a significância estatística das variáveis utilizadas no Mod.1, destacando-se, os efeitos do IFRS e das Big4 sobre as republicações, pois ambos tiveram efeito estatisticamente significativo e positivo. Além disso, verificou-se no teste de robustez que a TRA sofre um efeito defasagem, logo, a TRA do período anterior tem efeito significativo sobre a atual. Cabe destacar ainda o efeito Governança, que sugeriu um menor nível de TRA à medida que o nível de governança aumenta, o que ocorreu também com o fortalecimento dos controles internos (SOX). Outro achado que merece destaque foi o efeito negativo dos Accruals Totais sobre a TRA. Esse resultado sugere que o aumento dos Accruals Totais reduz a TRA. Essa relação, a priori, anômala, pode estar associada ao efeito dos custos políticos na medida em que maiores Accruals estimulam os agentes a buscarem evitar a republicação em decorrência dos efeitos adversos, independentemente do tipo de republicação feita (Hubber \& Bochnerm 2012).

Os resultados observados no presente estudo vão de encontro à maioria daqueles observados na literatura internacional (Bardos, 2011; Badertscher, Collins e Lys, 2012; Masulis, Sing \& Xie, 2012; Schrand \& Zechman, 2012; Chen, Cheng \& Lo, 2013; Dao et al., 2014; Baber et al., 2015; Collins et al., 2015; Cao et al., 2015; Agrawal \& Copper, 2015; Lin et al., 2015; Khalil \& Ozkan, 2016) e os poucos identificados na literatura nacional (Cunha, Magro, \& Fernandes, 2015; Marques, 2016).

O estudo contribui com a literatura nacional e internacional sobre o tema e abre espaço para se compreender em maior profundidade as determinantes da republicação no contexto nacional, especificamente em uma abordagem empírico-quantitativa. Do ponto de vista teórico, o estudo contribui com a teoria da agência na medida em que traz evidências de que os mecanismos de controle (Auditoria, Estrutura de Governança) da firma e os de incentivos aos agentes (Pacote de Remuneração) contribuem para reduzir o nível e probabilidade de se republicar. Na prática chama atenção à necessidade de se reforçarem os respectivos mecanismos e, principalmente, chama a atenção dos reguladores, pois a mudança do padrão contábil teve efeito positivo sobre as republicações.

O estudo apresenta limitações de como analisar apenas dados de empresas listadas, indisponibilidade de informações sobre remuneração dos gestores no período Pré-IFRS, além de não utilizar uma proxy mais robusta para o controle setorial. Para pesquisas futuras, sugere-se analisar o efeito reputação da firma nessa relação,além de inserir outras variáveis de controle, como mudança do auditor, opinião do auditor, os motivos das republicações, entre outros. 


\section{Referências}

Abed, S., Al-Badainah, J., \& Serdaneh, J. (June de 2012). The Level of Conservatism in Accounting Policies and Its Effect on Earnings Management. International Journal of Economics and Finance, 4(6), pp. 78-85. doi: http://dx.doi.org./10.5539/ijef.v4n6p78.

Aghion, P., \& Holden, R. (Spring de 2011). Incomplete Contracts and the Theory of the Firm: What Have We Learned over the Past 25 Years? The Journal of Economic Perspectives, 25(2), pp. 181-197. doi: http://dx.doi.org./10.1257/jep.25.2.181.

Agrawal, A., \& Cooper, T. (2015). Insider trading before accounting scandals. Journal of Corporate Finance, 34, pp. 169-190. doi: http://dx.doi.org./10.1016/j.jcorpfin.2015.07.005.

Alexander, C. R., Bauguess, S. W., Bernile, G., Lee, Y., \& Westberg, J. M. (2013). Economic effects of SOX Section 404 compliance:A corporate insider perspective. Journal of Accounting and Economics, 56, pp. 267-290. doi: http://dx.doi.org./10.1016/j.jacceco.2013.09.002.

André, P., Filip, A., \& Paugam, L. (April/May de 2015). The Effect of Mandatory IFRS Adoption on Conditional Conservatism in Europe. Journal of Business Finance \& Accounting, 42(3-4), pp. 482-514. doi: http://dx.doi.org./10.1111/jbfa.12105.

Armstrong, C., Guay, W. \& Weber, J. (2010). The role of information and financial reporting in corporate governance and debt contracting. Journal of Accounting and Economics (50), pp. 179-234. doi: http://dx.doi.org./10.1016/j.jacceco.2010.10.001.

Baber, W., Kang, K., Liang, L. \& Zhu, Z. (2015). External Corporate Governance and Misreporting. Contemporary Accounting Research, 32(4), pp. 1413-1442. doi: http://dx.doi.org./10.1111/19113846.12137.

Badertscher, B., Collins, D. \& Lys, T. (2012). Discretionary accounting choices and the predictive ability of accruals with respect to future cash flows. Journal of Accounting and Economics, 53, pp. 330-352. doi: http://dx.doi.org./10.1016/j.jacceco.2011.11.003.

Ball, R. (2006). International Financial Reporting Standards (IFRS): Pros and Cons for Investors. Accounting and Business Research, 36(1), pp. 5-27. doi: http://dx.doi.org./10.1080/00014788.2006.9730040.

Bardos, K. (2011). Quality of financial information and liquidity. Review of Financial Economics, 20, pp. 49-62. doi: http://dx.doi.org./10.1016/j.rfe.2011.01.001.

Beatty, A. \& Liao, S. (2014). Financial accounting in the banking industry: A review of the empirical literature. Journal of Accounting and Economics, 58, pp. 339-383. doi: http://dx.doi.org./10.1016/j.jacceco.2014.08.009.

Bergstresser, D. \& Philippon, T. (2006). CEO incentives and earnings management. Journal of Financial Economics, 80, pp. 511-529. doi: http://dx.doi.org./10.1016/j.jfineco.2004.10.011.

Brickley, J. \& Zimmerman, J. (2010). Corporate Governance Myths: Comments on Armstrong, Guay, and Weber. Journal of Accounting and Economics, 50(2), pp. 235-245. doi: http://dx.doi.org./10.1016/j. jacceco.2010.10.002.

Brown, L., \& Caylor, M. (2009). Corporate Governance and Firm Operating Performance. Review of Quantitative Finance and Accounting, 32, pp. 129-144. doi: http://dx.doi.org./10.1016/j.jacceco.2010.10.002.

Burks, J. (2010). Disciplinary measures in response to restatements afterSarbanes-Oxley. J. Account. Public Policy, 29, pp. 195-225. doi: http://dx.doi.org./10.1016/j.jaccpubpol.2010.03.002. 
Cao, Y., Myers, L. \& Omer, T. (2012). Does Company Reputation Matter for Financial Reporting Quality? Evidence from Restatements. Contemporary Accounting Research, 29(3), pp. 956-990. doi: http:// dx.doi.org./1911-3846.2011.01137.

Cao, Z., Feroz, E. \& Davalos, S. (2015). Corporate governance and default risk of firms cited in the SEC's Accounting and Auditing Enforcement Releases. Rev Quant Finan Acc, 44, pp. 113-138. doi: http:// dx.doi.org./10.1007/s11156-013-0401-9.

Chalmers, K., Clinch, G. \& Godfrey, J. (2011). Changes in value relevance of accounting information upon IFRS adoption: Evidence from Australia. Australian Journal of Management, 36(2), pp. 151-173. doi: http://dx.doi.org./10.1177/0312896211404571.

Chen, C., \& Chih, H. (2005). Investor protection, prospect theory and earnings management: an international comparison of the banking industry. Journal of Banking \& Finance, 29, pp. 2675-2697. doi: http://dx.doi.org./10.1016/j.jbankfin.2004.10.004.

Chen, K., Elder, R., \& Hung, S. (2014). Do post-restatement firms care about financial credibility? Evidence from the pre- and post-SOX eras. J. Account. Public Policy, 33, pp. 107-126. doi: http://dx.doi. org./10.1016/j.jaccpubpol.2013.12.002.

Chen, X., Cheng, Q., \& LO, A. (2013). Accounting Restatements and External Financing Choices. Contemporary Accounting Research, 30(2), pp. 750-779. doi: http://dx.doi.org./10.1111/j.19113846.2012.01171.X.

Coase, R. (November de 1937). The nature of firm. Economica, 4(16), pp. 386-405. Recuperado em 15 de junho, 2016, de http://www.colorado.edu/ibs/es/alston/econ4504/readings/The\%20Nature\%20 of\%20the\%20Firm\%20by\%20Coase.pdf.

Collins, D., Masli, A., Reitega, A., \& Sanchez, J. (2015). Earnings Restatements, the Sarbanes-Oxley Act, and the Disciplining of Chief Financial Officers. Journal of Accounting, Auditing \& Finance, pp. 162171. doi: http://dx.doi.org./10.1016/j.adiac.2008.08.005.

Cooper, D., \& Schindler, P. (2003). Métodos de pesquisa em Administração (7a. ed.). (L. d. Rocha, Trad.) Porto Alegre: Bookman.

Cunha, P., Magro, C. \& Fernandes, L. (2015). A Influência do Refazimento das Demonstrações Contábeis no Gerenciamento de Resultados das Empresas Listadas na BM\&FBovespa. Congresso USP de Iniciação Científica, 12, São Paulo, SP, Brasil. Recuperado em 20 de julho, 2016, de http://www.congressousp.fipecafi.org/web/artigos152015/153.pdf.

Dhaliwal, D. (1985, March). The Agency Cost Rational for Refunding Discounted Bonds. The Journal of Financial Research, 8(1), pp. 43-50. http://dx.doi.org./10.1111/j.1475-6803.1985.tb00424.x.

Dantas, J., Chaves, S., Silva, M. \& Carvalho, R. (2011). Determinações de Refazimento/Republicação de Demonstrações Financeiras pela CVM: O papel dos auditores independentes. Revista Universo Contábil, 7(2), pp. 45-64. doi: http://dx.doi.org./10.4270/RUC.2011212.

Dao, M., Huang, H., Chen, K. \& Huang, T. (2014). Can Management Turnover Restore the Financial Statement Credibility Of Restating Firms? Further Evidence. Journal of Business Finance \& Accounting, 41(7), pp. 893-925. doi: http://dx.doi.org./10.1111/jbfa.12081.

Dechow, P. \& Schrand, C. (2004). Earnings Quality. Virginia: the Research Foundation of CFA Institute. Recuperado em 10 de julho, 2016, de http://csinvesting.org/wp-content/uploads/2015/04/Defining-Earnings-Quality-CFA-Publication.pdf.

Dechow, P., Ge, W. \& Schrand, C. (2010). Understanding earnings quality: A review of the proxies, their determinants and their consequences. Journal of Accounting and Economics, pp. 344-401. doi: http:// dx.doi.org./10.1016/j.jacceco.2010.09.001. 
DeFond, M. (2010). Earnings quality research: Advances,challenges and future research. Journal of Accounting and Economics, 50, pp. 402-409. doi: http://dx.doi.org./10.1016/j.jacceco.2010.10.004

Di Pietra, R., McLeay, S. \& Ronen, J. (2014). Accounting and Regulation: new insigths on governance, markets and institutions. New York: Springer.

Elayan, F., LI, J. \& Meyer, T. (2008). Accounting irregularities, management compensation structure and information asymmetry. Accounting and Finance, 48, pp. 741-760. doi: http://dx.doi.org./10.1111/ j.1467-629x.2008.00266.x.

Ettredge, M., Scholz, S., Smith, K., \& Sun, L. (2010). How Do Restatements Begin? Evidence of Earnings Management Preceding Restated Financial Reports. Journal of Business Finance \& Accounting, 37(3), pp. 332-355. doi: http://dx.doi.org./10.1111/j.1468-5957.2010.02199.x.

Fávero, L. (2013). Dados em painel em contabilidade e finanças. Brazilian Business Review, 10(1), pp. 131156.

Fávero, L., Belfiore, P., Lopes da Silva, F. \& Chan, B. (2009). Análise de dados: modelagem multivariada para tomada de decisão ( $1^{\mathrm{a}}$. ed.). Rio de Janeiro, Rio de Janeiro, Brasil: Campus Elsevier.

Fields, T., Lys, T. \& Vincent, L. (2001). Empirical research on accounting choice. Journal of Accounting and Economics, 31, pp. 255-307. doi: http://dx.doi.org./10.1016/S0165-4101(01)00028-3.

Francis, J., Michas, P. \& Yu, M. (2013). Office Size of Big 4 Auditors and Client Restatements. Contemporary Accounting Research, 30(4), pp. 1626-1661. doi: http://dx.doi.org./10.1111/1911-3846.12011.

Francis, J., Olsson, P. \& Schipper, K. (2006). Earnings Quality: fundations and trends in accounting (Vol. 1). Boston: Now Publisher Inc.

Graham, J., Harvey, C. \& Rajgopal, S. (2005). The economic implications of corporate financial reporting. Journal of Accounting and Economics, 40, pp. 3-73. doi: http://dx.doi.org./10.1016/j.jacceco.2005.01.002.

Hair Jr., J., Babin, B., Money, A. \& Samouel, P. (2005). Fundamentos de Métodos de Pesquisa em Administração (Reimpressão 2007 ed.). Porto Alegre: Bookman.

He, L. \& Chiang, H. (2013). Market Reaction to Financial Statemen Restatement: A Study on the Information and Insurance Role of Auditors. Advances in Management and Applied Economics, 3(4), pp. 37-50.

Healy, P. (1985). The effect of bonus schemes on accounting decisions. Journal of Accounting and Economics, 7, pp. 87-107. doi: http://dx.doi.org./10.1016/0165-4101(85)90029-1.

Hee, K. (2011). Changes in the predictive ability of earnings around earnings restatements. Review of Accounting and Finance, 10(2), pp. 155-175. doi: http://dx.doi.org./10.1108/14757701111129625.

Hellou Netto, F. \& Pereira, C. (2010). Impacto da republicação de demonstrações financeiras no preço das ações de empresas brasileiras. Revista Contemporânea de Contabilidade, 7(14), pp. 29-50. doi: http://dx.doi.org./10.5007/2175-8069.2010v7n14p29.

Huber, J. \& Bochner, J. (2012). Surviving a restatement (overview of restatement process). Insgths; the Corporate \& Securities Law Advisor, 26(4), pp. 15-26. Recuperado em 5 de abril, 2016, de www.wsgr. com/publications/PDFSearch/bochner-0412.pdf.

Hutton, A., Marcus, A. \& Teharanian. (October de 2009). Opaque financial reports, $\mathrm{R}^{2}$, and crash risk. Journal of Financial Economics, 94(1), pp. 67-86. doi: http://dx.doi.org./10.1016/j.jfineco.2008.10.003.

Iliev, P. (2010). The Effect of SOX Section 404: Costs, Earnings Quality, and Stock Prices. The journal of finance, 65(3), pp. 1163-1196. doi: http://dx.doi.org./10.1111/j.1540-6261.2010.01564.x 
Jensen, M. C. \& Meckling, W. (1976). Theory of the firm: managerial behavior, agency costs and ownership structure. Journal of Financial and Economics, 3(4), pp. 305-360. doi: http://dx.doi. org./10.1016/0304-405X(76)90026-X.

Jensen, M. \& Meckling, W. (1994). The nature of man. Journal of Applied Corporate Finance, 7(2), pp. 4-19. doi: http://dx.doi.org./10.1111/j.1745-6622.1994.tb00401.x.

Jiao, T., Koning, M., M. G. \& Roosenboom, P. (2012). Mandatory IFRS adoption and its impact on analysts' forecasts. International Review of Financial Analysis, 21, pp. 56-63. doi: http://dx.doi.org./10.1016/j. irfa.2011.05.006.

Key, K. (1997). Political cost incentives for earnings management in the cable television industry. Journal of Accounting and Economics, 23, pp. 309-337. doi: http://dx.doi.org./10.1016/S0165-4101(97)00012-8.

Jones, J. (1991). Earnings management during import relief investigations. Journal of Accounting Research, 29, pp. 193-228. http://dx.doi.org./ 10.2307/2491047.

Khalil, M. \& Ozkan, A. (2016). Board Independence, Audit Quality and Earnings Management: Evidence from Egypt. Journal of Emerging Market Finance, 15(1), pp. 84-118. doi: http://dx.doi. org./10.1177/0972652715623701.

Khanin, D., \& Mahto, R. (2012). Regulatory risk, bordeline legality, fraud and financial restatement. International Journal of Accounting and Information Management, 20(4), pp. 377-394. doi: http://dx.doi. org./10.1108/18347641211272713.

Kryzanowski, L., \& Zhang, Y. (2013). Financial restatements and Sarbanes-Oxley: Impact on Canadian firm governance and management turnover. Journal of Corporate Finance, 21, pp. 87-105. doi: http:// dx.doi.org./10.1016/j.jcorpfin.2013.01.007.

Lambert, R. (2001). Contracting theory and accounting. Journal of Accounting and Economics, 32, p. 87. doi: http://dx.doi.org./10.1016/S0165-4101(01)00037-4.

Lin, P., Lee, S., Chen, X. \& YurAustin, J. (2015). Highlights of financial restatements from 2000 through 2011. Management Accounting Quarterly, 17(1), pp. 1-12. Recuperado em 07 de julho, 2016, de https://www.questia.com/library/journal/1G1-449578080/highlights-of-financial-restatements-from-2000-through.

Lisic, L., Silveri, S., Song, Y. \& Wang, K. (2015). Accounting fraud, auditing, and the role of government sanctions. Journal of Business Research, 68, pp. 1186-1195. doi: http://dx.doi.org./10.1016/j.jbusres.2014.11.013.

Mackenzie, B., Coetsee, D., Njikizana, T., Chamboko, R., Colyvas, B. \& Hanekom, B. (2013). IFRS 2012: interpretação e aplicação. Porto Alegre: Bookman.

Manly, B. (2008). Métodos Estatísticos Multivariados - Uma Introdução (3 ed.). Porto Alegre: Bookman.

Marques, V. (2016). Qualidade das Informações Financeiras e o Ambiente Regulatório: Evidências Empíricas no Período de 1998-2013. Tese de Doutorado em Administração, Centro de Pós-Graduação e Pesquisas em Administração - CEPEAD, Universidade Federal de Minas Gerais. Belo Horizonte, MG, Brasil. Recuperado em 10 de setembro, 2016, de http://cepead.face.ufmg.br/btd/files/498/aid498n2a1.pdf.

Martinez, A.L. (2001). Gerenciamento dos resultados contábeis: estudos empíricos das companhias brasileiras abertas. Tese de Doutorado em Contabilidade e Controladoria, Faculdade de Economia, Administração e Contabilidade, Universidade de São Paulo. São Paulo, MG, Brasil. Recuperado em 20 de julho, 2016, de http://www.teses.usp.br/teses/disponiveis/12/12136/tde-14052002-110538/pt-br.php.

Martins, E. (2012). A Contabilidade Brasileira de Ontem e de Hoje; e de Depois? Em A. Lopes, A contabilidade e finanças no Brasil: estudos em homenagem ao professor Eliseu Martins (pp. 3-27). São Paulo, São Paulo, Brasil: Atlas. 
Masulis, R., Wang, C. \& Xie, F. (2012). Globalizing the boardroom-The effects of foreign directors on corporate governance and firm performance. Journal of Accounting and Economics, 53, pp. 527-554. doi: http://dx.doi.org./10.1016/j.jacceco.2011.12.003.

Modigliani, F. \& Miller, M. (1963). Corporate Income Taxes and the Cost of Capital: A Correction . The American Economic Review, 53(3), pp. 433-443.

Murcia, F. \& Carvalho, L. (2007). Conjecturas Acerca do Gerenciamento de Lucros, Republicação das Demonstrações Contábeis e Fraude Contábil. Contabilidade Vista \& Revista, 18(4), pp. 61-82.

Myers, S. C. \& Majluf, N. S. (1984). Corporate Financing and Investment Decisions when Firms have Information that Investors do not have. Journal of Finance Economics, pp. 187-221.

Nelson, M., \& Skinner, D. (2013). How should we think about earnings quality? A discussion of "Earnings quality : Evidence from the field". Journal of Accounting and Economics 56, pp. 34-41. doi: http:// dx.doi.org./10.1016/j.jacceco.2013.10.003.

Palmrose, Z., Richardson, V. \& Scholz, S. (2004). Determinants of market reactions to restatement announcements. Journal of Accounting and Economics, 37, pp. 59-89. doi: http://dx.doi.org./10.1016/j. jacceco.2003.06.003.

Pindyck, R., \& Rubinfeld, D. (2004). Econometria: modelos \& previsões (4a. Ed. ed.). Rio de Janeiro: Elsevier.

Pfarrer, M., Smith, K., Bartol, K., Khanin, D. \& Zhang, X. (May-June de 2008). Coming Forward: The effects of Social and Regulatory Forces on the voluntary restatement of Earnings Subsequent to Wrong doing. Organization Science, 19(3), pp. 386-404. doi: http://dx.doi.org./10.1287/orsc.1070.0323.

Ramanan, R. (2014). Corporate Governance, Auditing, and Reporting Distortions. Journal of Accounting, Auditing \& Finance, 29(3), pp. 306-339. doi: http://dx.doi.org./10.1177/0148558X14535779.

Ribeiro da Silva, A. (2010). Metodologia da pesquisa aplicada à contabilidade: orientaçõe de estudos, projetos, artigos, relatórios, mnografias, dissertações, teses ( $3^{\mathrm{a}}$. ed.). São Paulo: Atlas.

Ronen, J. (2014). Post-enron Reform: Financial Statement Insurance, and GAAP Re-Visited. Em R. Di Pietra, S. McLeay, \& J. Ronen, Accounting and Regulation: New Ingihts on Governance, Markets and Institutions. New York: Springer.

Schrand, C. \& Zechman, L. (2012). Executive overconfidence and the slippery slope to financial misreporting. Journal of Accounting and Economics, 53, pp. 311-329. doi: http://dx.doi.org./10.1016/j. jacceco.2011.09.001.

Shelton, S., Owen-Jackson, L., \& Robinson, D. (2011). IFRS and U.S. GAAP: Assessing the impact of report incentives on firm restatements in foreign and U.S. Markets. Advances in Accounting, incorporing Advances in International Accounting, pp. 187-192. doi: http://dx.doi.org./10.1016/j.adiac.2011.04.005.

Sunder, S. (2014). Teoria da Contabilidade e do Controle. São Paulo: Atlas.

Tan, L. (2013). Creditor control rights, state of nature verification, and financial reporting conservatism. Journal of Accounting and Economics, 55, pp. 1-22. doi: http://dx.doi.org./10.1016/j.jacceco.2012.08.001.

Thompson, J. \& McCoy, T. (2008). An analysis of restatements due to errors and auditor changes by Fortune 500 companies. Journal of Legal, Ethical and Regulatory Issues, 11(2), p. 45.

Watts, R. (1992). Accounting Choice Theory and Market-Based Research In Accounting. British Accounting Review 24, pp. 235-267. doi: http://dx.doi.org./10.1016/S0890-8389(05)80023-X.

Watts, R. \& Zimmerman, J. (January de 1978). Towards a Positive Theory of the Determination of Accounting Standards. The Accounting Review, 53(1), pp. 112-134. 
Wooldridge, J. (2010). Econometric analysis of cross section and data panel (2nd. ed.). Massachussets: Massachussets Institute of Technology.

Yoo, T. \& Jung, D. (2015). Corporate governance change and performance: The roles of traditional mechanism in France and South Korea. Scandinavian Journal of Managemente 31, pp. 40-53. doi: http:// dx.doi.org./10.1016/j.scarman.2014.08.005.

Young, S. \& Peng, E. (2013). An Analysis of Accounting Frauds and the Timing of Analyst Coverage Decisions and Recommendation Revisions: Evidence from the US. Journal of Business Finance \& Accounting, 32, pp. 399-437. doi: http://dx.doi.org./10.1111/jbfa.12020. 